\title{
Do synergies exist in related acquisitions? - A meta-analysis of acquisition studies
}

\author{
Homberg, Fabian ; Rost, Katja ; Osterloh, Margit
}

\begin{abstract}
Mergers and Acquisitions (MA) aim to increase wealth for shareholders of the acquiring company, in particular by creating synergies. It is often assumed that relatedness is a source of synergies. Our study distinguishes between business, cultural, technological and size relatedness. It discusses the reasons why these different forms of relatedness can lead to an acquisition success and conducts a meta-analysis of 67 prior MA studies. Results indicate that positive effects can be expected under specific conditions only and have a limited overall impact on acquisition success. A moderator analysis finds that synergies stemming from relatedness depend on industry-, country-, and investor-characteristics.
\end{abstract}

DOI: https://doi.org/10.1007/s11846-009-0026-5

Posted at the Zurich Open Repository and Archive, University of Zurich ZORA URL: https://doi.org/10.5167/uzh-29667

Journal Article

Published Version

Originally published at:

Homberg, Fabian; Rost, Katja; Osterloh, Margit (2009). Do synergies exist in related acquisitions? - A meta-analysis of acquisition studies. Review of Managerial Science, 3(2):75-116.

DOI: https://doi.org/10.1007/s11846-009-0026-5 


\title{
Do synergies exist in related acquisitions? A meta-analysis of acquisition studies
}

\author{
Fabian Homberg $\cdot$ Katja Rost $\cdot$ Margit Osterloh
}

Received: 3 June 2008/ Accepted: 3 February 2009/Published online: 28 February 2009

(C) Springer-Verlag 2009

\begin{abstract}
Mergers and acquisitions (M\&A) aim to increase the wealth of shareholders of the acquiring company, in particular by creating synergies. It is often assumed that relatedness is a source of synergies. Our study distinguishes between business, cultural, technological, and size relatedness. It discusses the reasons why these different forms of relatedness can lead to an acquisition success and we conduct a meta-analysis of 67 prior M\&A studies. Results indicate that positive effects can be expected under specific conditions only and have a limited overall impact on acquisition success. A moderator analysis finds that synergies stemming from relatedness depend on industry-, country-, and investor-characteristics.
\end{abstract}

Keywords Mergers and acquisitions - Meta-analysis - Business relatedness · Size relatedness - Technological relatedness - Cultural relatedness · Synergies

JEL Classification G34 · M19

F. Homberg $(\bowtie) \cdot$ K. Rost $\cdot$ M. Osterloh

IOU Institute for Organization and Administrative Science, University of Zurich,

Universitätsstrasse 84, 8006 Zurich, Switzerland

e-mail: fabian.homberg@iou.uzh.ch

K. Rost

e-mail: katja.rost@iou.uzh.ch

M. Osterloh

e-mail: osterloh@iou.uzh.ch

M. Osterloh

CREMA, Center for Research in Economics, Management and the Arts,

Zurich, Switzerland 


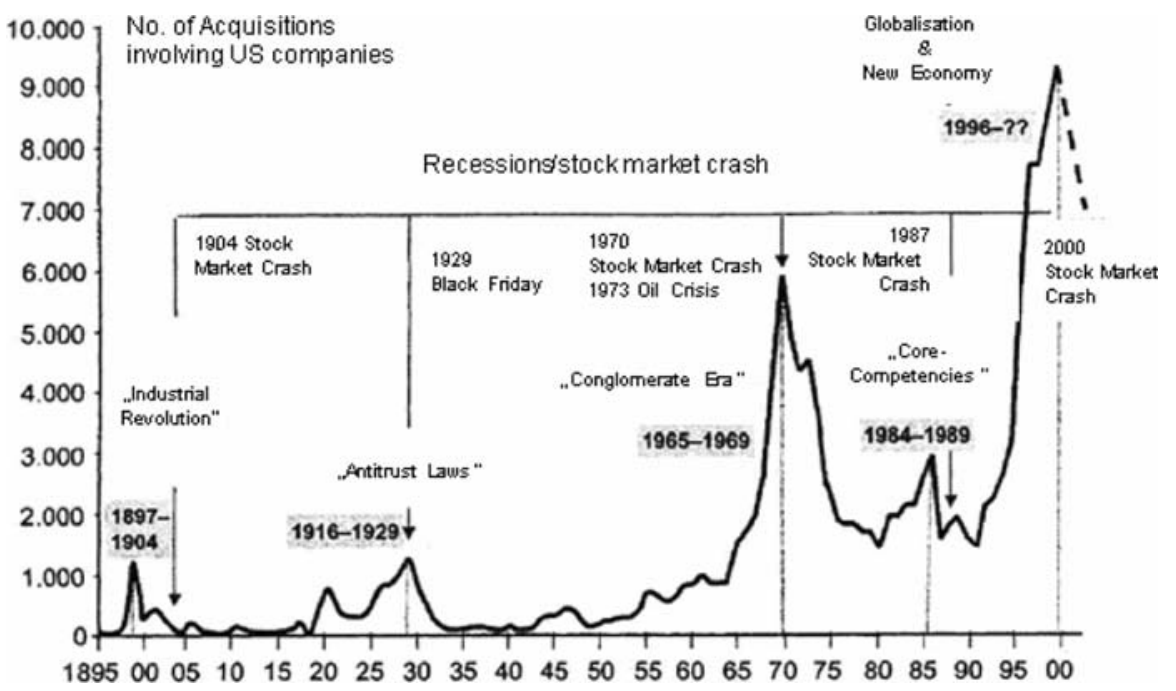

Fig. 1 M\&A waves in the last decades. Source: adopted from Müller-Stewens and Lechner (2003)

\section{Introduction}

Acquisitions are a specific types of investment, and as shown in Fig. 1, acquisitions often occur in peaks (Bruner 2002; Rappaport 1986). The recent peaks took place in 2000 and 2006 with worldwide deals climbing above billion \$3,000 (Tschöke and Csanad 2007). The most common argument for pursuing acquisitions is to increase the wealth of the shareholders of the acquiring company (Tuch and O'Sullivan 2007): acquisitions can create synergies, increase a firm's market share and bargaining power, or lead to improved risk diversification. Nonetheless, a large number of M\&A are considered as failures and do not succeed in increasing shareholder wealth. While Bruner $(2002,2005)$ talks about $30 \%$ of deals failing, Jansen (2002) estimates as high as 50-75\%. Overall, the majority of empirical literature on bidder performance in acquisitions has failed to provide consistent evidence for increased shareholder wealth (Tuch and O'Sullivan 2007). After reviewing the M\&A literature focusing on merger policy in the US in great detail, Mueller (1997) concludes: "It is possible, judging from the available evidence on the effects of mergers, that the US economy would be as or even more efficient today, if there had been no mergers over the last 50 years." Sudarsanam (1995) finds in the UK market that takeover gains are at best neutral for shareholders. ${ }^{1}$

The literature on M\&A explains the failure of deals due to a false evaluation of potential synergies when companies merge with or acquire other corporations (Köppen and Knyphausen-Aufseß 2004; Roll 1986; Sirower 2001). Synergies may have different sources. Financial synergies arise by reducing the cost of capital of the firm, e.g., through tax benefits or improved leverage (Chatterjee 1986). Other sources of

\footnotetext{
${ }^{1}$ Sudarsanam's (1995) review includes only four prior studies. His conclusions should be considered with care.
} 
synergies are larger economies of scale and scope, enhanced efficiency or the gaining of access to new markets, new customers or new technologies (Rumelt 1974; Salter and Weinhold 1978). In this paper we do not explicitly pay attention to synergies arising from economies of scope; instead, we focus on synergies that arise due to relatedness, because in M\&A projects the relatedness argument is far more common.

Usually, it is expected that synergies are highest in related acquisitions (Healy et al. 1997, p. 45). They are often a negotiating point between buyer and seller that impacts on the final price both parties agree upon. Therefore, corporate synergies have to be forecasted through careful estimations in order to protect shareholders from significant wealth destruction through acquisitions.

To forecast synergies the degree of similarity between two firms is often used (Lubatkin and Srinivasan 1997). ${ }^{2}$ It is assumed that in the case of so called "related" acquisitions the management has a sound understanding of the firm to be acquired because of its similarity (Flanagan and O'Shaugnessy 2003). However, relatedness can embrace different sources which can be divided into business, cultural, technological, and size relatedness. The effect of these four sources of synergies is unclear. This might explain why some authors find strong positive effects between relatedness and the profitability of acquisitions (Flanagan 1996; Healy et al. 1997; Morck et al. 1990; Singh and Montgomery 1987), whereas others diagnose the opposite (Hambrick and Cannella 1993; Limmack and McGregor 1995; Sudarsanam et al. 1996).

Our study contributes to M\&A research by answering the question as to when relatedness is a source of potential synergies. We first summarize prior research results on the effect of relatedness on the success of M\&A. Secondly, in a metaanalysis, we determine the degree to which shareholder wealth can be explained by business, cultural, technological and size relatedness. Our overall findings indicate that commonly agreed sources of synergies seem to have only a small impact. Relatedness does not automatically increase shareholder wealth. Simply referring to similar business concepts, cultures, technologies or sizes is not adequate for forecasting synergies. Our detailed analysis of how relatedness influences different performance measurements and of how its influence varies depending on different regions or industries, leads to the conclusion that relatedness can be a cause of wealth creation as well as of wealth destruction. As a consequence more attention should be paid to different performance measures (and thus to different investor types) and to the contingencies under which relatedness increases or decreases the performance of firms engaging in M\&A activity.

In the following sections, we develop a set of hypotheses regarding mechanisms through which relatedness affects M\&A performance and we test them using metaanalytic techniques. The meta-analytic approach provides an integration of the previous body of work and may help explain the inconsistent findings obtained in previous studies.

\footnotetext{
2 This is in contrast to financial synergies, where dissimilarity of firms is considered to be the most important source of benefits (Chatterjee 1986). "In sum, mergers of similar firms tend to have greater financial synergies when the correlation of cash flows is low and volatilities are somewhat lower than the base case" (Leland 2007). Unfortunately, cash flows in related acquisitions tend to be correlated by definition because the acquisition takes place in a similar or at least linked business. That is why financial synergies are most likely to be achieved in unrelated diversification.
} 
In Sect. 2 we present arguments and empirical evidence for synergies that may arise from the aforementioned four forms of relatedness. In Sect. 3 we describe the meta-analytic method. The major difference to prior meta-analyses is that our metaanalysis compares the effect of four relatedness dimensions on acquisition performance and acknowledges the multi-dimensionality of acquisition performance. In addition to the standard accounting and market based indicators, we employ knowledge indicators such as patents, new product developments and others. Section 4 presents the statistical results. Section 5 discusses the findings. Section 6 concludes that other explanations for the negligible overall effect of relatedness on acquisition success should be combined with the relatedness-hypothesis.

\section{Literature review and research framework}

In the following we do not distinguish between the various ways of acquiring control rights ${ }^{3}$ because this distinction is important only to lawyers, accountants, and tax specialists, and less relevant in terms of its economic impact (Bruner 2002, p. 1). Consequently, we use the general term "mergers and acquisitions" (M\&A) or simply "acquisition". 4

Figure 2 presents the model guiding this study. It focuses on synergy realization as a result of similar patterns of resource allocations and similar dominant logics (Harrison et al. 1993; Prahalad and Bettis 1986) as reflected in M\&A performance. Rumelt (1974) was among the first to distinguish different levels of relatedness ranging from the single business firm to the conglomerate firm. ${ }^{5} \mathrm{He}$ finds that related diversifiers perform better than unrelated ones. This study triggered a host of empirical research analyzing the relatedness-performance relationship. ${ }^{6}$

\footnotetext{
3 According to Jensen and Ruback (1983) a takeover is defined as a transfer of the target's control rights from the target's management team to the bidding firm's management. Such activities take place on the market for corporate control: managers' fears of becoming a target act as a control mechanism effectively aligning their interests with those of the shareholders. The term "acquisition" is a mere purchase (of control rights) whereas the term "merger" describes the combination of two firms to one legal entity that have been different legal entities before (see, e.g. Bruner 2002, p. 1). Berkovitch and Khanna (1991) define a merger as an offer made to the target's management. The merger offer leads to bargaining between the two parties. Negotiations take place in relative secrecy. In contrast, a tender offer is made directly to the target's shareholders and conveys more information to the public. Another way to acquire control over a target firm is the proxy contest in which the amount of voting rights is decisive (Bebchuk and Hart 2001).

${ }^{4}$ Most of the studies we included in the meta-analysis do also not explicitly distinguish between acquisitions and mergers and use the general term M\&A. Other authors treat M\&A the same way (Gugler et al. 2003).

5 Rumelt's typology includes the major categories: dominant business, related constrained, related linked and unrelated (conglomerate) businesses and has been applied in various studies (Baysinger and Hoskisson 1989; Bettis and Hall 1982; Montgomery and Singh 1987).

6 For example, Datta et al. (1991) review the literature on diversification and find inconclusive evidence. Palich et al. (2000) conduct a meta-study and establish an inverted U-curve, i.e. diversification is profitable when a firm has been a single business firm and then diversifies into related businesses. But diversification lowers profitability when the firm switches from related to unrelated diversification. In the following sections we present some conflicting findings on the effects of the relatedness variables on acquisition performance.
} 


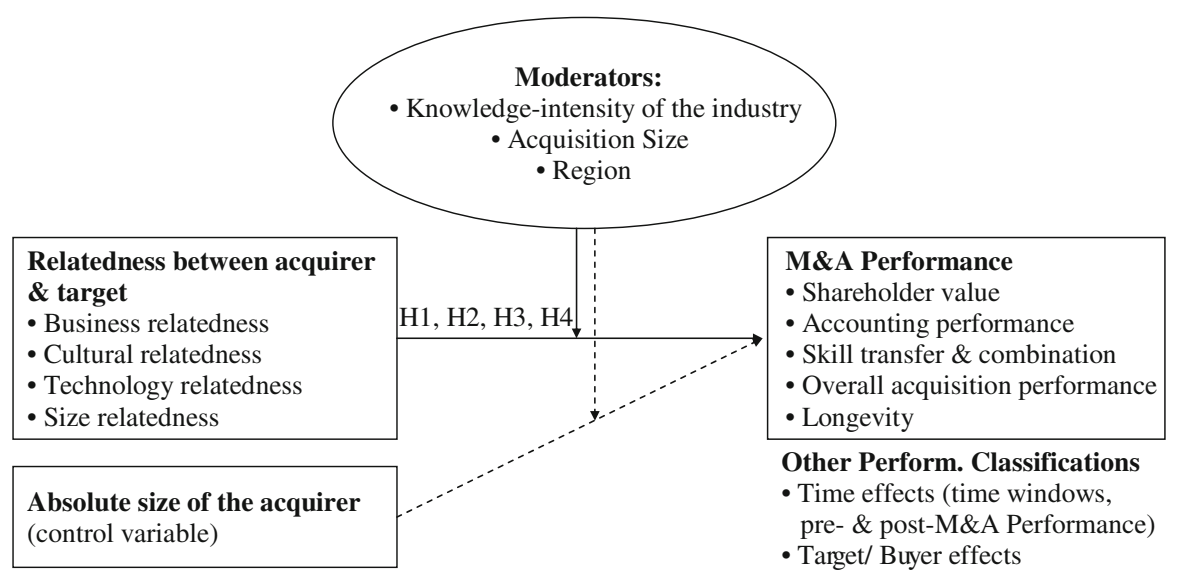

Fig. 2 Analyzed impact of relatedness on M\&A performance

The M\&A-literature discusses the impact of four major kinds of relatedness on acquisition success: business relatedness (Kusewitt 1985; Rumelt 1974), size relatedness (Hagedoorn and Duysters 2002; Hitt et al. 1991), cultural relatedness (Buono et al. 1985; Chatterjee et al. 1992), and technological relatedness (Cassiman et al. 2005; Hagedoorn and Duysters 2002). In the following sections we review the hypothesized impact of each kind of relatedness on acquisition success.

As shown in Fig. 2, in the empirical analysis we will test for the effects of relatedness on different performance types, commonly measured in terms of shareholder value, accounting-based performance, amount of skill transfer and combination, overall acquisition performance, and the divestment of the acquired company by the parent. In addition we develop other performance classifications for buyer and target. Finally, we test for moderating effects.

\subsection{Business relatedness}

Business relatedness concerns acquisitions in similar markets and industries. The idea is to transfer knowledge generated in the old business to the newly acquired one. Existing knowledge facilitates a realistic estimation of operational synergies, reduces unit costs due to the use of existing distribution channels for products and protects from overpayments (Montgomery and Singh 1987). It also reduces risk because income streams become more stable when acquisitions occur in related product markets (Salter and Weinhold 1978). Furthermore, the number of potential rivals decreases and the market power of the combined firm increases. Practitioners follow this line of thought.

Results demonstrating the profitability of the acquisition of related businesses are mixed. Using ROA as a dependent variable Kusewitt (1985) finds a positive effect in related acquisitions. Pennings et al. (1994) and Miller (2006) find similar effects employing return on capital, R\&D intensity and ROA as dependent variables. Davis et al. (1992) conclude that both market and production relatedness provide benefits 
to the firm. They also find that production relatedness is more effective when aiming at profitability instead of sales. Gugler et al. (2003) analyze a worldwide sample of M\&As with respect to profits and sales and conclude that related mergers perform better than conglomerate or vertical ones. In contrast, other authors employing both R\&D intensity and ROA do not find positive effects in related acquisitions (Harrison et al. 1993).

In developing our working hypothesis, we follow Tuch and O'Sullivan (2007), who conclude after a review of the literature on M\&A and performance that there is some support for a positive effect on wealth creation in business related acquisitions:

Hypothesis 1 Business relatedness has a positive effect on acquisition performance.

\subsection{Cultural relatedness}

Managers often disregard the importance of an acquisition's cultural impact (Chatterjee et al. 1992). However, integration costs seem to be considerably lower when similar corporate cultures are combined, resulting in a positive impact on the acquisition performance (Larsson and Finkelstein 1999). Synergies arise from similarity in decision making processes, informal controls and norms that govern behavior (Datta 1991). When the 'way the work is done' is similar, misinterpretations of motives and intentions as well as interpersonal conflicts are reduced (Bruton et al. 1994). Cultural distance should be avoided (Larsson and Lubatkin 2001) because the target's culture tends to be changed according to the acquirer's cultural preferences (Chatterjee 1986) with dysfunctional consequences for the integration process (Buono et al. 1985).

These findings are supported by many studies which show a positive impact on firm performance stemming from cultural relatedness (Cloodt et al. 2006; Hagedoorn and Duysters 2002; Morosini et al. 1998; Slangen 2006; Vermeulen and Barkema 2001). However, other authors find a negative effect in cultural relatedness (Buono et al. 1985; Chatterjee et al. 1992). They explain this finding by the knowledge-advancing effect of diversity. In a meta-analysis, Stahl and Voigt (2008) show that cultural relatedness (a) in nine M\&A-studies has an positive impact on announcement effects measured as cumulative abnormal returns (CARs), but (b) in $15 \mathrm{M} \& \mathrm{~A}$-studies has no effects on the accounting performance of a firm.

Based on the argument, that integration costs are lower when firms combine similar corporate cultures, we derive the following working hypothesis:

Hypothesis 2 Cultural relatedness has a positive effect on acquisition performance.

\subsection{Technological relatedness}

The "relatedness" argument has also been discussed with respect to technology and innovation. The question is whether innovations are triggered due to a better usage of similar technologies or enhanced employment of different knowledge bases. 
Synergies might arise due to the accumulation of similar or complementary operations (Larsson and Finkelstein 1999). Synergies from accumulating similar operations are achieved by reduction in unit costs and the prevention of inefficiencies due to time consuming learning efforts. However, synergies, e.g., the development of new products might also be elicited by the combination of complementary resources.

The 'economies of sameness' argument is supported by different studies (Capron and Mitchell 2000; Markides and Williamson 1994; Puranam and Srikanth 2007). Hagedoorn and Duysters (2002) find positive effects in technological similarity which they attribute to similar knowledge management mechanisms. However, Cassiman et al. (2005) and others (Baysinger and Hoskisson 1989; Cloodt et al. 2006; Hitt et al. 1996) find empirical evidence that complementary technologies yield economic benefits in acquisitions.

According to the 'economies of sameness' argument we derive the following working hypothesis:

Hypothesis 3 Technological relatedness has a positive effect on acquisition performance.

\subsection{Size relatedness}

Some authors assume that targets and buyers of similar size lead to better knowledge integration and show the most efficient integration processes (Ahuja and Katila 2001). In this case the acquirer is better prepared to recognize the value and content of the acquired knowledge, to assimilate it, and to apply it (Cohen and Levinthal 1990). It is easier to identify redundancies when both firms are of equal size (Krishnan et al. 2007). This leads to workforce reductions resulting in cost savings. These kinds of synergies are easily identified (Ficery et al. 2007).

Other authors argue, however, that size differences lead to higher synergies. Seth (1990) supports the view that a small buyer acquiring a large target increases its market power as well as economies of scope and scale. In contrast, Bruton et al. (1994) argue that acquiring a relatively small target is associated with better acquisition performance. The larger the acquired company the more complex the organizational structures are. As a consequence the danger arises for the management to lose control (Chakrabarti 1990; Ravenscraft and Scherer 1989). More management and financial resources have to be devoted to the target, in particular when the target firm is financially distressed. This is often the case with the acquisition of young start-up companies (Fluck and Lynch 1999). It is assumed that only a significantly larger buyer can provide these managerial and financial resources. ${ }^{7}$

Results on the profitability of size relatedness are mixed. Some authors (Chatterjee and Wernerfelt 1991; Finkelstein and Haleblian 2002; Heeley et al. 2006; Kumar 1985; Papadakis 2005; Puranam and Srikanth 2007; Ravenscraft and

\footnotetext{
7 As single entities these projects would not exist. Fluck and Lynch (1999) consider this approach consistent with diversified firms suffering from a conglomerate discount in financial markets and thus displaying a lower value than focused firms. Nonetheless, in this case, the combined entity has a higher value as compared to stand alone firms.
} 
Scherer 1989; Slangen 2006) find evidence for increased profitability when both buyer and target are of similar size.

According to Scanlon et al. (1989) small firms acquiring related firms tend to outperform large firms that acquire firms in unrelated businesses. ${ }^{8}$ The study of Seth (1990) shows a similar result. However, he demonstrates that synergistic gains are greater for large firms acquiring in related businesses as opposed to small firms executing related acquisitions. Kusewitt (1985), Bruton et al. (1994) and others (Baysinger and Hoskisson 1989; Hagedoorn and Duysters 2002; Hitt et al. 1991; Moeller et al. 2004; Vermeulen and Barkema 2001) find that size relatedness is only slightly connected to performance. Fuller et al. (2002) even find larger CARs the smaller the target. ${ }^{9}$

According to the 'integration' argument, we derive the following working hypothesis:

Hypothesis 4 Size relatedness has a positive effect on acquisition performance.

\section{Research method}

\subsection{Applied method, former meta-analyses and methodical (dis)advantages}

Our research is based on a meta-analysis of previous empirical studies that examined the relationship between relatedness of the target firm and the acquiring firm on subsequent acquisition performance. In contrast to other meta-analyses we compare the effects of four different relatedness dimensions on acquisition performance and we understand acquisition performance as a multi-dimensional construct which includes among others knowledge indicators. The most comprehensive meta-analytic review of M\&A by King et al. (2004) solely analyses the effects of business relatedness on abnormal returns and accounting measures. Larsson and Lubatkin (2001) as well as Stahl and Voigt (2008) concentrate on cultural effects. They do not consider any kind of knowledge indicators or longevity measure.

The advantages of meta-analysis are (1) quantification of surveys and results, (2) conceivability by persons not involved in science, (3) replicability and impartiality. Disadvantages are (1) comparability of the surveys, (2) integration of surveys of differing quality, (3) "publication bias" in favor of published, significant results (4) "non-independent effects" in case a survey documents several correlations (Eisend 2004). Our study minimizes two disadvantages: firstly, non-independent effects are reduced by applying subgroup-analyses. Secondly, comparability of different surveys is enhanced by distinguishing between different performance-measurements and by applying moderator analyses.

\footnotetext{
${ }^{8}$ In Scanlon et al. (1989) abnormal returns for small-related acquisitions are positive but not significant whereas for large acquisitions CARs are significantly negative.

9 However, this result only holds concerning public targets.
} 


\subsection{Sample and sample bias}

We collected the study sample by combining three research steps: (1) we conducted computerized database searches in the Web of science using the key words "mergers", "acquisition", "M\&A", "related/unrelated", "relatedness". (2) We screened the cited and citing literature of prior meta-analysis on mergers and acquisitions (Datta et al. 1992; King et al. 2004; Stahl and Voigt 2008). (3) We screened the cited and citing literature of articles that examined the relationship between relatedness and acquisition performance (e.g. Lubatkin 1987; Lubatkin and Srinivasan 1997). We stopped the screening procedure only when no new studies were found.

Our final sample has four major biases which should be considered when interpreting the results. Firstly, our sample has a strong "publication bias" in favor of results published in refereed journals and in the English language. Books, book sections, working papers and non-refereed conference proceedings were excluded. Secondly, only studies that were available were included, i.e. journals or periods of journals not licensed by the university were excluded. Finally we stopped our search procedure after not finding additional studies matching our criteria.

The final sample consists of 67 empirical studies $\left(n=23,391\right.$ M\&As). ${ }^{10}$ The studies document 479 statistical correlations between synergy variables, respectively the size of the acquiring company and acquisition performance. Our sample size is comparable with the samples of prior meta-analyses on M\&As. The sample of Datta et al. (1992) consists of 41 studies and 409 correlations. The recent sample of Stahl and Voigt (2008) consists of 46 studies and a combined sample size of 10,710 M\&As. The analysis of King et al. (2004) takes into account 93 studies, 852 correlations and a combined sample size of 15,305 M\&As. ${ }^{11}$ Concerning the effects of relatedness on acquisition performance, King et al. (2004) include 41 studies and a combined sample size of 6,581 M\&As.

The included studies cover a wide variety of industries: global chemicals, HighTech sector, IT- and pharmaceutical sector, semiconductor industry, industrial manufacturing sector, non-financial firms or a random sample of all industries. Concerning sample size the smallest sample includes $25 \mathrm{M} \&$ As, the largest 6,428 M\&As. The median sample size across all studies is 479 . The time period covered ranges from 1948 up to 2002. More descriptive information on the study sample is listed in Table 1.

\subsection{Operationalization of relatedness}

We coded the studies in terms of cultural, business, technological, and size relatedness between target and buyer. A wide range of indicators was employed. Table 10 in the Appendix gives a detailed overview. For the statistical analysis we

\footnotetext{
${ }^{10}$ Included studies are listed in the reference section. Two studies are counted as four studies because both studies use two independent samples.

11 In their study the authors talk about a combined sample size of 206,910 M\&As. This number is obtained by adding up sample sizes of different correlations from one study.
} 
Table 1 Descriptive statistics of the 67 M\&A studies included in the meta-analysis

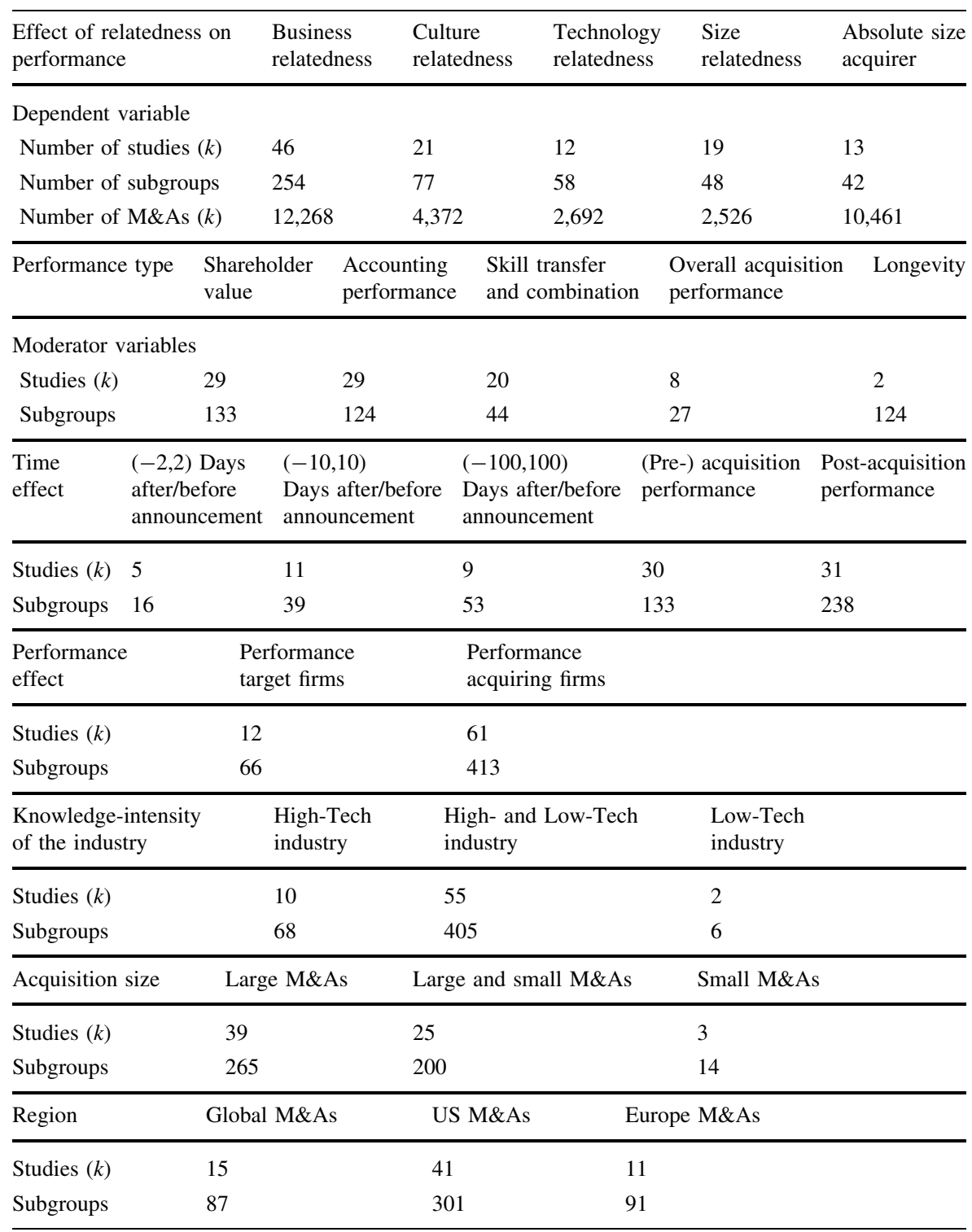

recoded all distance measurements as relatedness measurements by inverting the correlation sign. Recoding was especially important with respect to cultural relatedness and to some measures of size relatedness.

Business relatedness is commonly assessed in four different ways: (1) objective measures of relatedness by computing a diversification index based on the 2 and 4digit SIC code of the companies, (2) refinement of these measures by including an entropy index and a Herfindahl-Index according to Palepu (1985), (3) qualitative 
approaches for classification as proposed by Rumelt (1974), Porter (1985) and Bettis and Hall (1982), or (4) subjective measures of relatedness based on surveys or expert judgments.

Cultural relatedness is commonly assessed in three different ways: (1) a national cultural distance index by applying the approach of Kogut and Singh (1988) and by using the differences in country scores of Hofstede's (1980) four dimensions of national culture, i.e. uncertainty avoidance, power distance, individualism and masculinity, (2) bivariate variables distinguishing between domestic and foreign expansions, (3) subjective measures of cultural differences based on survey questions.

Technological relatedness is commonly assessed in three different ways: (1) objective measures of relatedness by computing a diversification index based on the IPC-classes of the companies patent stocks following Hall et al. (2001), (2) numbers of patents that appeared in both the acquired and the acquiring firm's knowledge base, (3) subjective measures of a common technology base based on surveys or expert judgments.

Size relatedness was coded in two ways: (1) a ratio of target to acquirer size by using assets, revenues, sales, number of employees, (2) surveys or expert judgments by employing scales ranging from "the acquiring firm is smaller in size" to "the acquiring firm is more than ten times the size of the acquired firm." All measurements of size relatedness were recoded in the following way: larger scores indicate a larger relative size of the target.

Absolute size of the acquirer was included as an additional variable. Larger acquirers might have greater power to absorb a new unit and thus are more able to realize potential synergies (Seth 1990). We included the well-known size effect as a control variable in order to visualize the relative effects of relatedness on acquisition performance and for reasons of interpretation. Most studies measured size by using assets, sales or number of employees of the acquiring company.

\subsection{Operationalization of acquisition performance}

The dependent variable "acquisition performance" can be assessed against a wide variety of benchmarks. For example an acquisition can provide access to new markets or to new technologies while being unprofitable from a financial viewpoint at the same time. In contrast, an acquisition that provides tax benefits and other financial values does not necessarily lead to new technologies or access to new markets. Because of this multi-dimensionality we use several performance constructs.

The success of acquisitions normally is assessed using the event study method. Event studies analyze the market's reaction around the merger announcement date and calculate CARs (see, e.g. Brown and Warner 1980; MacKinlay 1997). The drawback of this method is its reliance on the semi-strong form of the market efficiency hypothesis which is disputable. Another drawback is its strong focus on financial investors. Financial investors are interested in short-term monetary gains (King et al. 2004; Schoenberg 2006). However, these gains might not be sustainable and can represent stock market anomalies or stock market reactions with respect to 
the chosen accounting method (Robinson and Shane 1990). ${ }^{12}$ For example, some private equity companies “(...) simply take a business private, load it with debt, strip its assets, then sell it a few months later for multiples of the purchase price (...)" (Kiechel 2007, p. 18). For this reason the market's reaction around the merger announcement date might be a good measurement of M\&A-gains of financial investors but not necessarily of strategic investors and blockholders.

Long term sustainable competitive advantage in M\&A is achieved via operating efficiency, new product developments and patenting activities, basic R\&D, knowledge transfer and combination and the longevity of executed M\&A. Therefore, the long-term success of acquisitions can be assessed via these indicators.

We classified the studies in terms of five different performance types. As with relatedness the studies employ a wide range of indicators in order to measure one specific performance type. Table 11 in the Appendix gives a detailed overview.

Objective standard performance was measured by distinguishing between the shareholder value of the M\&A and the accounting performance of the combined company.

Shareholder value is commonly measured via abnormal returns (CAR, MCAR), wealth effects, performance in market share, earning per share growth, stock returns, or percent change in market value.

Accounting performance was measured as (1) the absolute EBITDA, ROA, ROE, ROS, sales of the combined company as well as the growth of these indicators, or (2) the growth in sales, etc. as indicated by respondents.

Skill transfer and combination captures acquisition performance with respect to innovation and knowledge as the basis of sustainable competitive advantage. The included studies employ the following measures: (1) leverage of innovation capabilities and knowledge based on patent authorship data or on patent citations, (2) changes in R\&D intensity, new product intensity, number of patents, patent intensity growth, (3) subjective measures of skill and resource transfer, of new product development, of innovation, technology or R\&D field growth based on surveys or expert judgments.

Overall acquisition performance measures the impact of $M \& A$ on combined performance. Usually subjective measurements are employed: (1) a combination of multiple survey questions capturing the extent of synergy realization through realized benefits from purchasing, production, marketing, market power, administration, vertical economies, new market access, cross-selling, know-how transfer, knowledge creation, etc., (2) expert evaluations of executives and analysts regarding the financial and strategic benefits from the acquisition.

Longevity (1) measures whether the acquired company was divested by the parent company or (2) captures the number of years a venture persisted. These measurements were recoded in the following way: larger scores indicate longer survivals.

\footnotetext{
12 So called "purchase" accountings tend to perform better, but "pooling" accounting has been abolished in the meantime (Lindenberg and Ross 1999). Andrade (1999) finds that the accounting method is used by acquirers to improve earnings dilution effects.
} 


\subsection{Operationalization of other performance classifications}

In order to check for alternative performance effects, we recoded the dependent variable "acquisition performance" to capture time effects and performance effects.

To capture time effects we recoded the dependent variable acquisition performance in the following way: (1) market reactions around 2 days before and 2 days after the merger announcement date, (2) market reactions around 10 days before and 10 days after the merger announcement date, (3) market reactions around 100 days before and 100 days after the merger announcement date, (4) strategic performance measures, e.g., accounting measures or skill transfer and combination, observed within (or even before) the acquisition year, (5) strategic performance measures observed after the acquisition year.

To capture performance effects that might influence acquisition performance we coded the studies in terms of (1) performance measured for acquirers/combined firms and (2) performance measured for target firms (Stahl and Voigt 2008).

\subsection{Operationalization of moderator variables}

The inconsistent results in M\&A research might be partially a consequence of contingencies which moderate the effect of relatedness on acquisition performance. Moderator variables firstly help to substantiate main results. Secondly, they help to explain insignificant or small effects as positive effects may be obtained for one characteristic of the moderator while negative effects may be obtained for a different characteristic. In order to check for such effects, we coded four moderator variables independent of the introduced measurements which might moderate acquisition performance.

Knowledge-intensity of the industry (Cloodt et al. 2006): we classified the studies as follows: (1) studies solely observing M\&As in the High-Tech industry, (2) studies observing random samples, i.e. M\&As in High- and Low-Tech firms, (3) studies solely observing M\&As in the Low-Tech industry.

Acquisition size Acquisitions of large targets are often expected to be more successful in related acquisitions (Seth 1990). We arrange the studies as follows: (1) studies solely observing large M\&As, (2) studies observing random samples, i.e. large and small M\&As, (3) studies solely observing small M\&As.

Region (Hofstede 2001): The studies were distinguished between (1) studies observing global M\&As, (2) studies solely observing US M\&As, (3) studies solely observing European M\&As. There was no study for M\&As in Asia.

\subsection{Coding and inter-rater agreement}

Depending on the available information we collected data on (1) correlation values and overall sample size, (2) mean values, standard deviations and group sample size, or (3) mean values, $t$ values and group sample size. Twenty-six studies of the 67 studies were coded by two independent raters (the second author and a student about to obtain his diploma). The interrater reliability was measured by the percentage agreement (Orwin 1994). This percentage amounts to 93\% suggesting 
that the coding process produced reliable data. The remaining studies where coded by the second author. ${ }^{13}$

\subsection{Method}

We used the software "comprehensive meta analysis" (Borenstein et al. 2007). It transforms different statistical information into Fisher's $\mathrm{Z}$ using the approach of Hunter and Schmidt (2004). We checked for publication outliers by plotting a study's effect size against its standard error. The studies were almost symmetrically distributed demonstrating the absence of distorting publication bias. In contrast to some meta-analyses we did not correct the unreliability of studies based on selfreported measures (King et al. 2004), even though we checked for systematic errors. The standardised mean effects of self-report and of objective measures do not vary significantly $(P=0.62)$.

To ensure an acceptable level of independence among studies with multiple subgroups, effect sizes were averaged when a study provided multiple indicators of the same variable, e.g., different indicators for business relatedness (King et al. 2004). When a study documented multiple subgroups, we determined a total effect $d$. For correlations $r$ this effect is calculated as follows:

$$
d_{i}=\frac{2 r_{i}}{\sqrt{1-r_{i}^{2}}}
$$

Finally, we calculate an average effect Cohen's $\bar{d}$ for the total sample and for each kind of outcome measurement respectively. The effect is corrected for sampling errors. We are using fixed-effect-models, i.e. the correlations are weighted by the sample size of a study. The fixed-effect approach builds on the assumption of an overall population parameter, whereby the effects of a single study randomly differ from the error in the overall sample. The total effect is calculated from the study-specific weights $\mathrm{w}$, as follows:

$$
\text { Cohen's } \bar{d}=\frac{\sum\left(w_{i} d_{i}\right)}{\sum w_{i}}
$$

The results were checked for their internal homogeneity. A significant $Q$ value is evidence of variability of study-level effect sizes and thus indicates the existence of moderator variables.

$$
Q=\sum_{i=1}^{k} w_{i}\left(d_{i}-\bar{d}\right)^{2}
$$

We tested for significant moderator effects by comparing the mean effect sizes between the subgroups by means of a critical ratio tests (Borenstein et al. 2007). We performed subgroup analyses independent of the number of included studies. The convention is that each subgroup should contain a minimum of three studies (Dalton

\footnotetext{
13 In some cases variables had to be coded in opposite directions in order to measure the effect of relatedness (and not of distance) on performance (and not on without-performance).
} 
et al. 2003). For this reason we only interpret subgroup effects which are calculated on this minimum.

\section{Results}

Firstly, we show the overall effects of each relatedness dimension on acquisition performance. Secondly, we illustrate how each relatedness dimension contributes to different performance measures. Thirdly, we demonstrate how each relatedness dimension contributes to acquisition performance depending on contingencies. The results are discussed in Sect. 5.

\subsection{Relatedness and overall performance}

Overall relatedness, i.e. the composite index of all relatedness types, is not correlated with overall acquisition performance $(-0.001)$. Furthermore, business relatedness $\left(0.018^{*}\right)$ and technology relatedness $\left(0.070^{* *}\right)$ are positively linked with overall acquisition performance, while cultural relatedness $(-0.132 * * *)$ and size relatedness $(-0.070 * *)$ are negatively linked with overall acquisition performance. The findings substantiate hypotheses $\mathrm{H} 1$ and $\mathrm{H} 3$ and reject hypotheses $\mathrm{H} 2$ and H4. Table 2 shows that the absolute size of the acquiring company is negatively linked with overall acquisition performance $\left(-0.035^{* * *}\right)$.

\subsection{Relatedness and performance measures}

Table 3 documents how relatedness affects different performance types. Overall relatedness has no impact on the shareholder value $(-0.010)$, the transfer of skills and resources $(-0.005)$, and on overall acquisition performance $(-0.018)$, whereas it positively influences accounting performance $\left(0.033^{*}\right)$ and negatively longevity ( $-0.219 * * * ; 2$ studies).

Distinguishing relatedness types we find that business relatedness enhances the transfer and combination of skills and resources $(0.123 * * *)$ and overall acquisition performance $(0.163 * * *)$ while having no influence on shareholder value and accounting performance. Cultural relatedness has strong negative effects on shareholder value $(-0.307 * * *)$ and overall acquisition performance $(-0.149 * * *)$. The performance effects of technology relatedness are mixed: technology relatedness increases the shareholder value $\left(0.231^{* * *}\right)$ and the accounting performance $\left(0.295^{* *}\right)$, while decreasing the transfer and combination of skills and resources $\left(-0.318^{* * *}\right)$. Size relatedness has negative effects on accounting performance $(-0.250 * * *)$, indicating that larger acquirers relative to the target are in some respects more successful. These findings match the findings about absolute size: acquirers with a large absolute size earn higher accounting gains $(0.231 * * *)$ than acquirers with a small absolute size. However, acquirers with a large absolute size display lower shareholder value $\left(-0.516^{* * *}\right)$ and have a lower skill transfer and combination measure $\left(-0.091^{* * *}\right)$ than acquirers with a small absolute size. The 


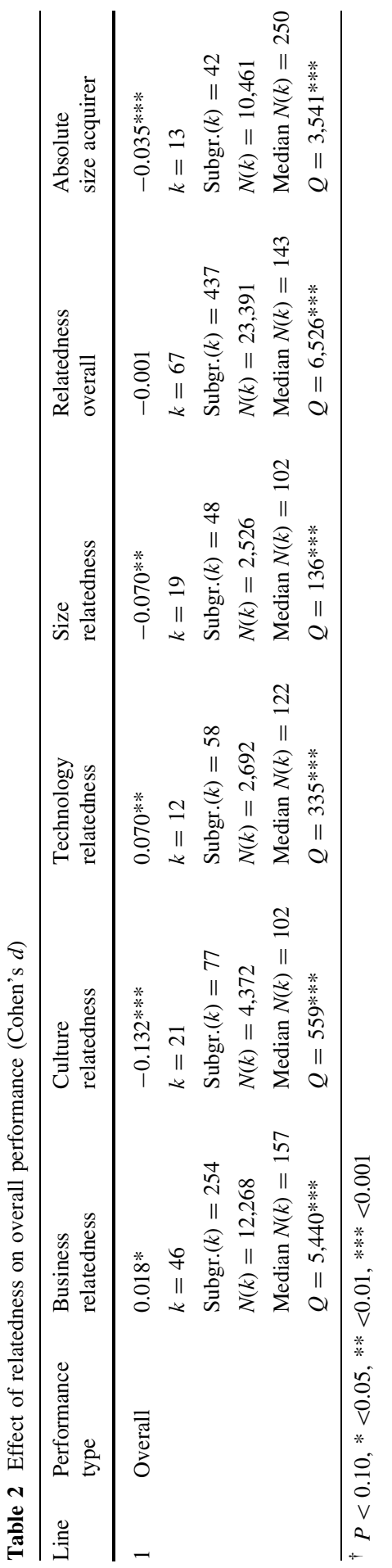




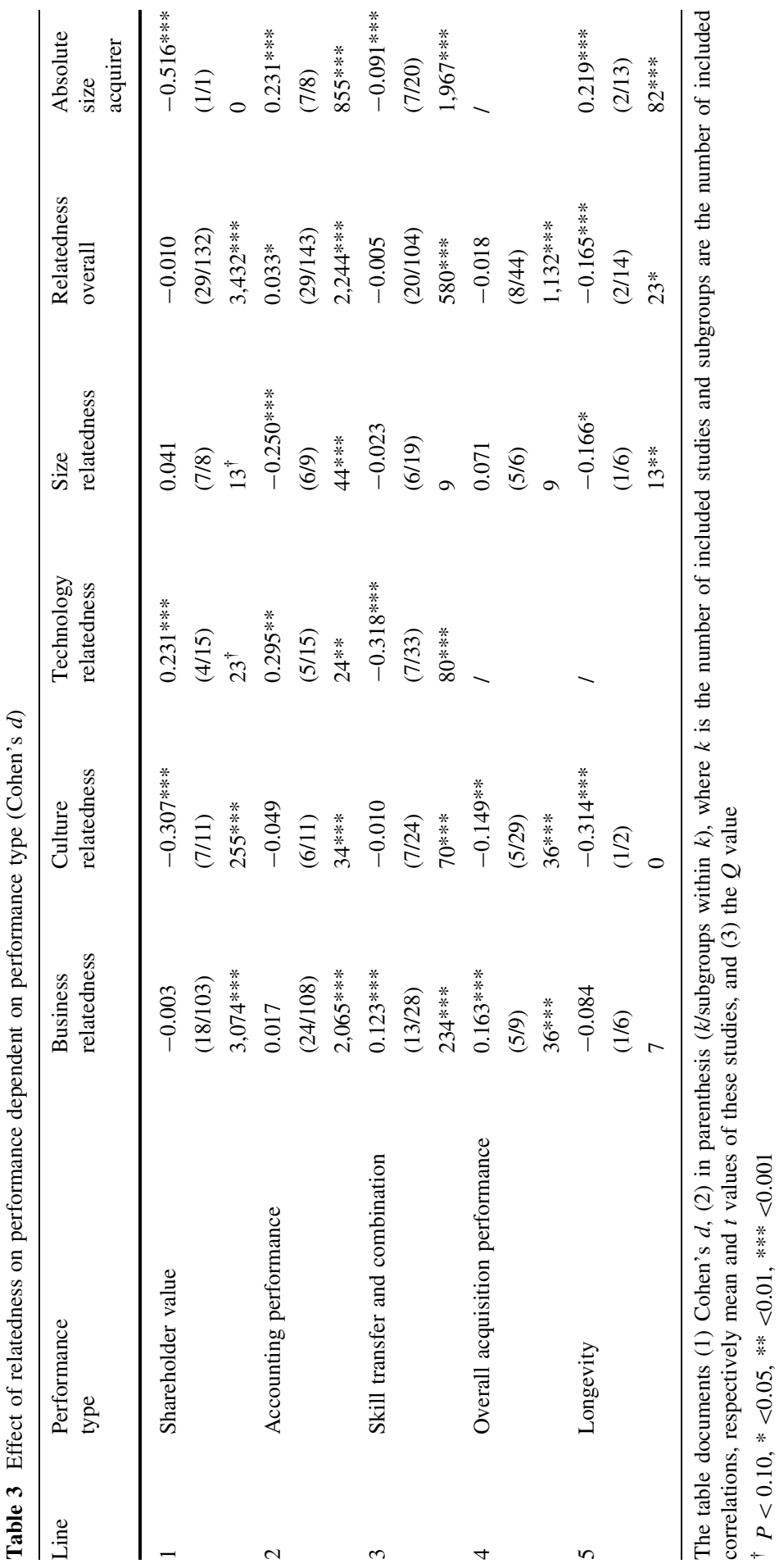


effects of relatedness on the longevity of M\&As are not discussed because the sample mainly consists of one study.

Table 4 documents how relatedness impacts performance dependent on time. In the short-run overall relatedness has positive effects as indicated by the increase of shareholder value in the 5 -day-window ${ }^{14}$ around the announcement date $(0.67 * * *)$. However, studies using larger time windows discover the opposite $\left(-0.031^{\dagger} /-\right.$ $0.137 * * *)$. Studies relying on other performance measurements than stock markets find no effects of relatedness on the performance in the acquisition year (0.020) and on post-acquisition performance (0.007).

On the level of each relatedness variable we find that business relatedness has only short-term performance effects as indicated by the increase of shareholder value in the 5-day-window $\left(0.067^{* * *}\right)$ and the increase of the strategic performance within the acquisition year $\left(0.068^{* * *}\right)$. In the long run business relatedness decreases performance as indicated by its negative effects on shareholder value in the 201-day-window ${ }^{15}$ around the announcement $\left(-0.170^{* * *}\right)$ or it has no effects as indicated by its influence on post-acquisition performance (0.012). Cultural relatedness has stronger negative effects in the short-term $(-0.374 * * * /-0.083 *)$ than in the long run $\left(-0.158 / 0.060^{\dagger}\right)$, while technology relatedness has positive effects in the long run $(0.194 * *)$. The negative effects of size relatedness are more pronounced in the short-term $\left(-0.162^{* * *}\right)$ than in the long run $\left(-0.081^{* *}\right)$. Finally, compared with smaller acquirers larger acquirers perform poorer within the acquisition year $(-0.042 * * *)$, but show no performance difference in the postacquisition period (0.049).

Table 5 documents how relatedness impacts the performance of targets and buyers. Overall relatedness is negatively associated with the performance of targets $\left(-0.090^{* * *}\right)$ and has no impact on the performance of the acquiring respectively the combined company (0.006).

Distinguishing relatedness types we find that cultural relatedness $(-0.474 * * *$ vs. $\left.-0.006^{*}\right)$ is linked with a poorer performance of targets supporting the former result.

\subsection{Relatedness dependent on contingencies}

Table 6 shows how relatedness depends on the knowledge intensity of the industry. Striking is the low number of M\&A-studies conducted within the Low-Techindustry even though acquisitions are very common, e.g., the current tendency of building contractors acquiring facility service providers. Because of the small sample size we interpret only the results of the High-Tech industry and the mixed sample, i.e. studies sampling High- and Low-Tech firms. The results indicate that relatedness overall has no effects on acquisition performance both in the mixed sample (-0.005) and in High-Tech-industries (0.030).

\footnotetext{
${ }^{14}$ The 5-day-window covers days -2 to +2 relative to the transaction announcement date as mentioned in Sect. 3.5.

15 The 201-day-window covers days -100 to +100 relative to the transaction announcement date as mentioned in Sect. 3.5.
} 


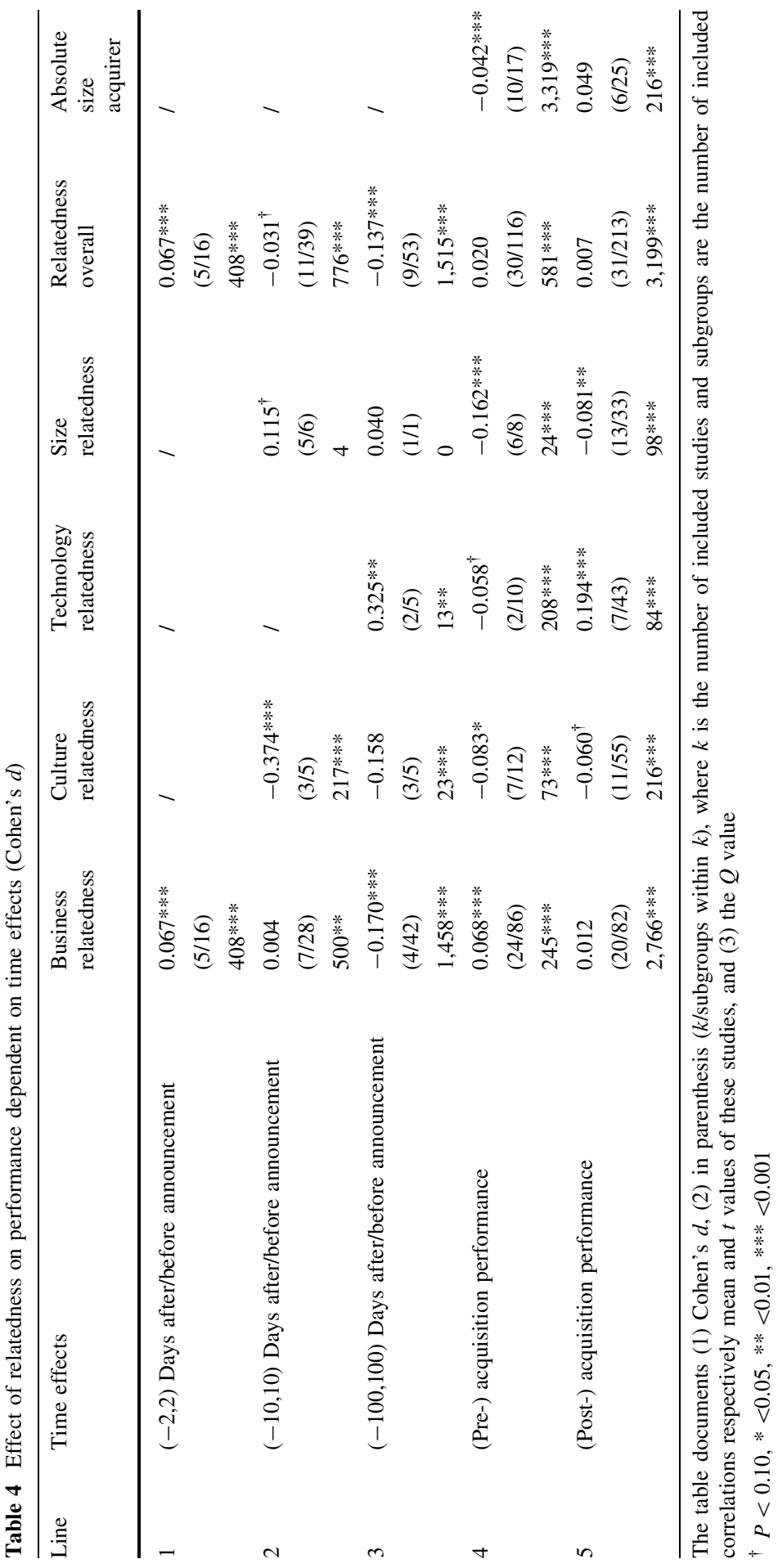




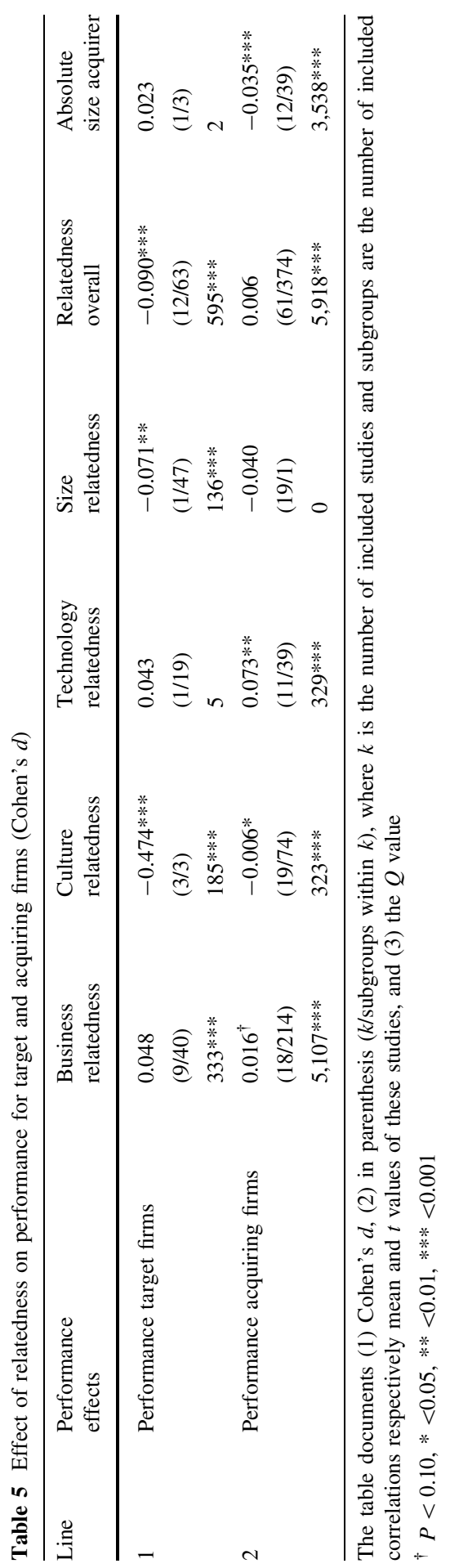




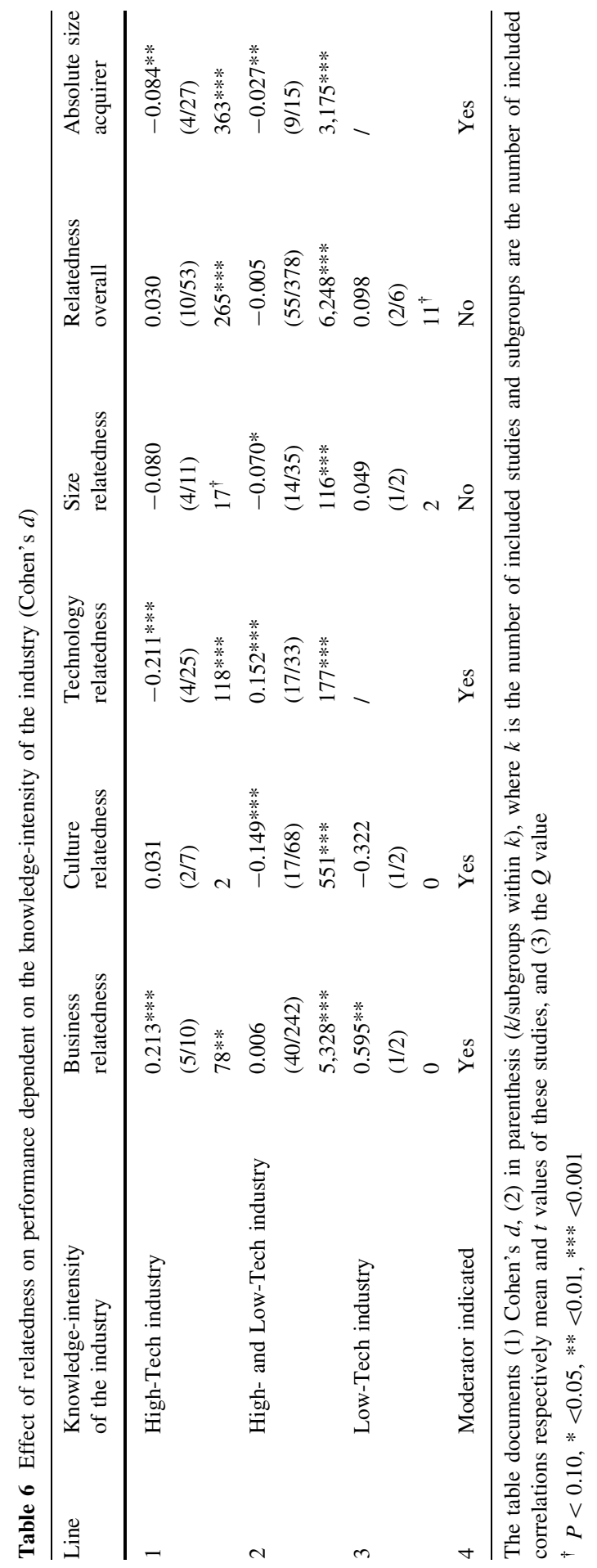


When relatedness types are distinguished, the results show that business relatedness increases the performance in the High-Tech industry $(0.213 * * *)$ but has no effects in the mixed sample (0.006), while size relatedness has no effect in the High-Tech industry but decreases performance in the mixed sample $\left(-0.070^{*}\right)$. Finally, technology relatedness leads to performance declines in the High-Tech industry $(-0.211 * * *)$ while increasing performance in the mixed sample $(0.152 * * *)$. The absolute size of the acquirer involves higher performance declines in the High-Tech sector $\left(-0.084^{* *}\right)$ compared to the mixed sample $\left(-0.027^{* *}\right)$.

Table 7 shows how relatedness depends on acquisition size. Most studies analyze samples of large but not of small M\&A; we therefore interpret the results of large and mixed samples only. The analysis demonstrates that overall relatedness has no effects in large M\&As (-0.011) and in mixed samples (0.006).

A more detailed analysis shows that business relatedness decreases the performance in large M\&A $\left(-0.030^{*}\right)$ while increasing the performance in the mixed sample $(0.062 * * *)$. Cultural relatedness has smaller negative effects in large M\&A $\left(-0.097^{*}\right)$ compared with the mixed sample $\left(-0.167^{* * *}\right)$. Technology relatedness shows positive performance effects in large M\&A $(0.144 * * *)$ while showing negative effects in the mixed sample $(-0.163 * * *)$. Finally, the absolute size of the acquirer has more pronounced negative performance effects in samples looking at large M\&As $\left(-0.095^{* *}\right)$ than in mixed samples $\left(-0.020^{\dagger}\right)$.

Table 8 demonstrates how relatedness depends on regions. The findings indicate that overall relatedness has a neutral effect in samples referring to global or US acquirers $(0.005 / 0.003)$ while it seems to decrease the performance in samples referring to European acquirers $\left(-0.042^{\dagger}\right)$.

When relatedness types are distinguished, the results show that business relatedness has significant and positive effects for global-acquirers only $\left(0.165^{* * *}\right)$. Cultural relatedness decreases the performance independent of region $(-0.123 * * /-0.156 * * /-0.142 * *)$. The results reveal that technology relatedness significantly increases the performance of US-acquirers $(0.164 * * *)$. Size relatedness shows significant and negative effects by US-acquirers $\left(-0.125^{* * *}\right)$. This finding is substantiated by the effects of absolute size: while size pays off for US-acquirers $\left(0.073^{*}\right)$, it involves losses for global- as well as for European-acquirers $(-0.035 * * * /-0.676 * * *)$.

\section{Discussion}

Table 9 summarizes the study's findings. The overall message is that synergies indeed exist in mergers and acquisitions. However, these synergies can arise due to either similarities or due to dissimilarities between the acquirer and the target. The optimal amount of relatedness or of differences strongly depends on (a) the interests of major investors as indicated by the performance measurements of financial (e.g. with respect to shareholder value) and strategic investors (e.g. with respect to skill transfer and combination; Table 3, Sect. 4.2), (b) the organizational goals as indicated by time effects (Table 4, Sect. 4.2), (c) other interests groups (Table 5, Sect. 4.2), e.g., the employees of the target, as indicated by target and buyer effects, 


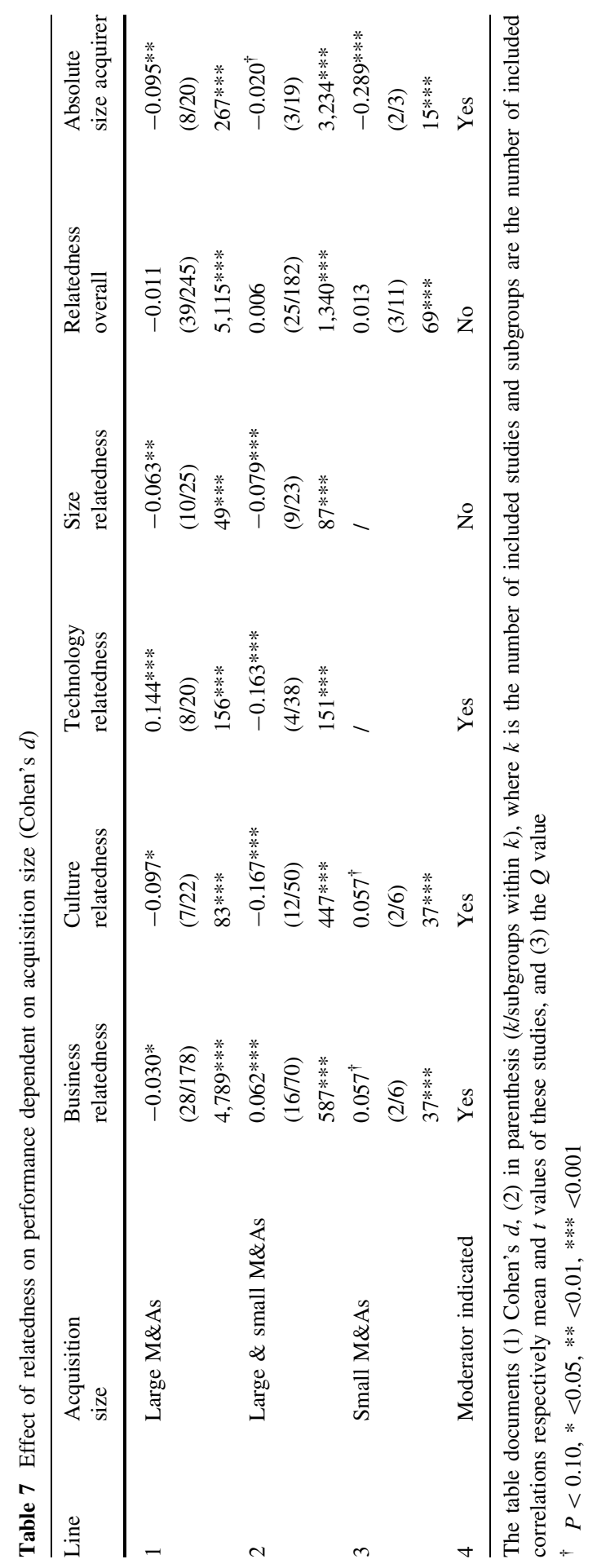




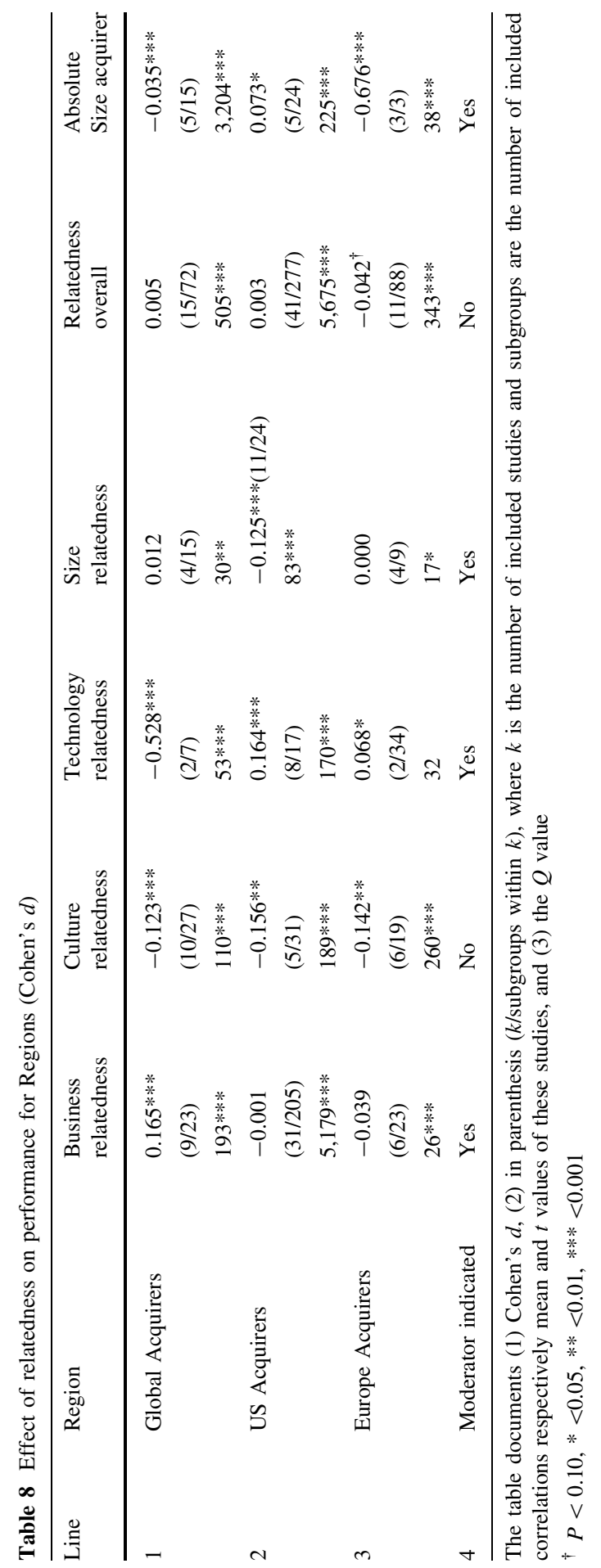




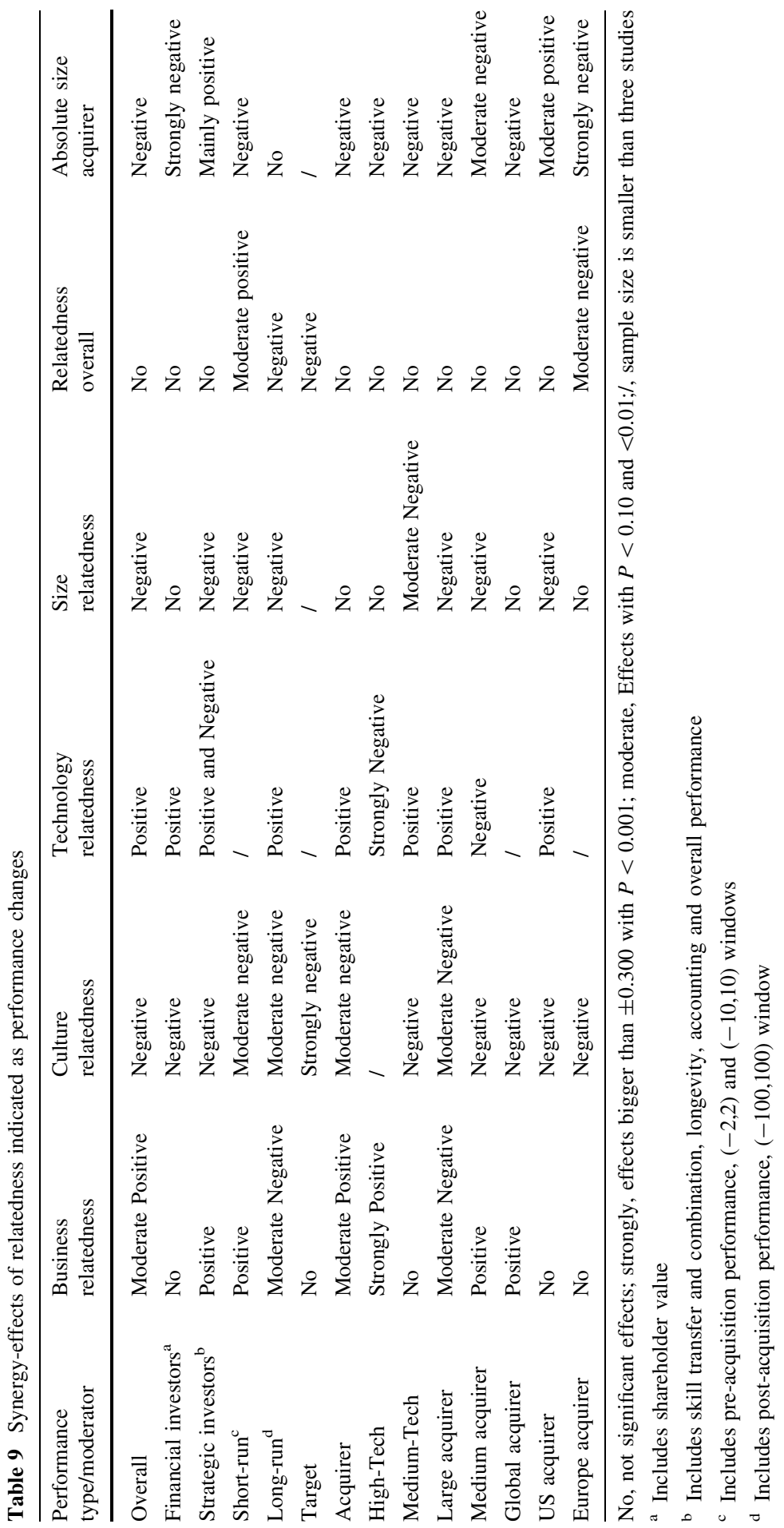


(d) industry characteristics as indicated by the knowledge-intensity of firms (Table 6, Sect. 4.3), (e) firm size (Table 7, Sect. 4.3), (f) institutional- and countryspecific characteristics as indicated by region (Table 8, Sect. 4.3).

The results allow more precise predictions according to three topics:

Firstly, we concentrate on overall performance and on the contribution each single relatedness construct makes to it. Secondly, we consider different investor types, i.e. strategic investors vs. financial investors, different time horizons of performance measures, and the performance of the target or of the acquirer respectively. Thirdly, we turn to the moderators.

Ad 1: The overall effect of relatedness on performance is negligible. It is also possible that synergies exist but that their effect is too small to pay-off a (high) acquisition premium. Nonetheless, the single dimensions of relatedness have different impacts. Moderate positive effects on overall performance stem from both business and technological relatedness. In contrast, cultural relatedness displays a strong negative effect on overall performance, and size relatedness exhibits a moderate negative effect. To summarize the first topic:

- Synergies due to relatedness arise in M\&A when firms work in similar businesses and build on similar technologies but at the same time have dissimilar cultures.

- The acquirer should be larger than the target.

- Synergies will decrease if the absolute size of a buyer is too large.

These findings are supported by prior research: The meta-analysis of Stahl and Voigt (2008) supports the finding that cultural distance might be an overall "success factor" by showing that cultural relatedness reduces socio-cultural integration efforts. Principal-agent theory further supports the negative influence of absolute size on acquisition success by reasoning that especially managers of big companies are more entrenched and thus find ways to bypass the interests of shareholders (Tosi et al. 2000). The absolute size finding is also in line with the firm size distribution, which is significantly skewed to the right with a large peak for the smallest size class (Laincz and Rodrigues 2005), indicating that a healthy growth of big firms is naturally limited.

Ad 2: Different investor types apply different performance criteria. We define financial investors as being mainly interested in shareholder value whereas strategic investors are mainly interested in a composite of skill transfer and combination, longevity, accounting performance and overall performance. Table 9 classifies different investor types and their benefits from the single relatedness dimensions according to our results. Financial investors profit from technological relatedness and small M\&A (i.e. the acquirer should be smaller in absolute size). Strategic investors benefit from business relatedness, from size differences (i.e. the acquirer should be larger than the target) and from large M\&A (i.e. the acquirer should be larger in absolute size). Both financial and strategic investors benefit if both companies have dissimilar cultures.

Furthermore, synergies differ with respect to short and long run performance measures. Short run measures comprise of short-time frames $(-2,2$ and $-10,10)$ as well as the (pre-) acquisition performance measures (see Table 4) and thus are more 
interesting for financial investors. Long run measures comprise of long time frame $(-100,100)$ and the post-acquisition performance measures and thus are more interesting for strategic investors (see Table 4). A financial theorist would argue that the short-time frames also reflect long run shareholder expectations. However, even in financial studies there is a distinction between short run and long run event studies: "while the exact definition of "long horizon" is arbitrary, it generally applies to event windows of 1 year or more." (Kothari and Warner 2004, p. 7). Thus, an exact allocation of benefits to financial or strategic investors based on time frames cannot be made with certainty.

In the short run synergies arise from business relatedness. In the long run synergies arise from technological relatedness. Synergies in M\&A can be expected both in the short and in the long run if the cultures between both companies differ and if the acquirer is larger in size than the target.

Synergies also differ with respect to the acquirer's and target's performance. Whereas acquirers and their investors benefit from synergies due to business relatedness, the target does not benefit. Only in the case of cultural distance are the investors of both groups able to increase their performance.

Ad 3. Synergy effects by relatedness are moderated by knowledge intensity, absolute size and region. They are summarized in Table 9.

The first moderator is the knowledge intensity of the industry. Synergies arise

- in M\&A in the High-Tech sector if both companies work in similar businesses but build on complementary technologies. The acquirer should be not too large in absolute size.

- in M\&A in the Medium-Tech sector if both companies have dissimilar cultures but build on similar technologies. The acquirer should be overall not too large in absolute size but larger than the target.

As a result, in knowledge intensive sectors similarity in valuable knowledge stocks boosts problems (e.g. technology relatedness) while similarity in surrounding factors (e.g. business models) reduces problems. The opposite is true for sectors which build less on knowledge.

The second moderator considers the absolute size of acquisitions. Synergies arise

- in large M\&A if both companies work in dissimilar businesses, have dissimilar cultures, but build on similar technologies. The acquirer should be larger than the target.

- in medium M\&A if both companies work in similar businesses but have dissimilar cultures and build on complementary technologies. The acquirer should be larger than the target.

- in large as well as in medium M\&A the synergies will decrease if the absolute size of a buyer is very large.

These results show that technology relatedness helps to overcome some of the problems in large M\&A. This finding is in line with the result that absolute firm size hinders the transfer and combination of knowledge in M\&A. In contrast, small firms profit from technological complementarities. 
The third moderator is the region according to the sample of M\&A used in each study. Synergies arise

- in global M\&A if both companies work in similar businesses but have dissimilar cultures. However, if the absolute size of a buyer is very large the synergies will decrease

- in US M\&A if both companies have dissimilar cultures but build on similar technologies. The buyer company should be larger than the target. Buyers with a larger absolute size earn higher synergies.

- in European M\&A if both companies have dissimilar cultures. The buyer company should be larger than the target. However, if the absolute size of a buyer is very large the synergies will decrease.

These results substantiate the argument that the effects of relatedness on acquisition performance are dependent on the region. As indicated by the opposite results of firm size on acquisition success in US and European M\&A countryspecific institutions are important. Many European companies are characterized by strong labor unions, co-determination and protection against dismissals. ${ }^{16}$ These institutions affect the market for corporate control by complicating M\&A of large firms. The findings imply that research results, especially results published in American journals, should be transferred to Europe with care.

To summarize the results of all three topics, our findings indicate that synergies depend on a wide variety of factors such as industry-, country, law- and investorcharacteristics and are considerably low. The relatedness hypothesis should also be discussed by including different interest groups, e.g., financial and strategic investors and contingencies like knowledge intensity of the industry or country specific effects. As a consequence synergies due to relatedness are not able to explain the huge acquisition activities in the last decades to a sufficient extent. Other explanations have to be found.

\section{Conclusion}

\subsection{Contributions}

Our study first highlights the ineffectiveness of synergies due to relatedness on the overall performance level. The analysis clearly shows that together such synergies are negligible.

Second we analyze the effect of four different dimensions of relatedness, i.e. business, cultural, technological and size relatedness, on different aspects of acquisition performance. Moderate positive effects on overall acquisition performance stem from business and technological relatedness. Cultural relatedness displays a strong negative effect on overall performance, and size relatedness

\footnotetext{
${ }^{16}$ Of the former EU-25 11 countries have strong co-determination laws: Austria, Czech Republic, Denmark, Finland, Germany, Hungary, Luxemburg, Netherlands, Slovak Republic, Slovenia, Sweden. In the UK, Greece, France, Italy and Spain such labor laws are absent. In the UK the influence of labor unions is dependent on the business segment.
} 
exhibits a moderate negative effect. Furthermore, since different investor types apply different performance criteria, an acquisition should satisfy both groups. However, synergies due to relatedness only arise for different investor types in the case of cultural distance.

Thirdly, our study points at the complexity of synergy assessments. We have shown that synergies are dependent on a variety of additional factors (such as country characteristics or time effects).

Fourthly, we applied multi-faceted performance criteria. We not only distinguished between accounting and market based measures but introduced knowledge indicators, e.g., skill transfer and combination, as measures of success. Knowledge indicators capture acquisition performance with respect to innovation and knowledge. Thus, they can be interpreted as the grounds on which sustainable competitive advantage is built as opposed to mere financial indicators.

Fifthly we provide evidence that the absolute size of an acquirer is extremely important and cannot be neglected. Our results suggest that smaller acquirers are more likely to profit from M\&A, therefore underlining that growth of firms is naturally limited.

As a consequence for practice, the board of directors as well as shareholders are well advised not to rely on promises of synergies due to relatedness on an overall level given by their executives. These results are in line with analyses of, e.g., Kürsten (2008) and others (see, e.g. King et al. 2004) who provide analytical and empirical evidence that shareholders are best advised to doubt promises of synergies made by executives when acquiring other firms.

\subsection{Limitations}

Our study has a number of limitations as mentioned in Sects. 3.1 and 3.2. Firstly, our sample has a strong "publication bias" in favor of results published in refereed journals and in the English language. Secondly, only studies that were available were included, i.e. publications licensed by the university.

We tried to minimize some disadvantages through properly applied methods of analysis and by including control and moderator variables. Firstly, non-independent effects are reduced by applying subgroup-analyses. Secondly, comparability of different surveys is enhanced by distinguishing between different performancemeasurements and by applying moderator analyses.

\subsection{Further research}

Further research could take numerous directions. One could be to intensify the research on different contingency factors like country differences, investor characteristics or sector affiliations. Thus, other methods than meta-analysis could be applied. For example, Bruner (2005) presents a series of detailed case studies in his analysis of factors contributing to M\&A failures.

A second option would be to start with the finding that synergies are overestimated. Two explanations for the huge amount of M\&A activities have already been proposed. The first explanation is the empire building of managers 
(Sudarsanam 1995). According to this view managers pursue M\&As for self-serving reasons such as high salaries, prestige or power which are facilitated by takeovers (Morck et al. 1990). In this case the decision-maker is purposely acting against shareholder interests. This implies that no matter how good the controls are the decision maker will try to find ways to bypass them. Thus, future research could investigate the effects of for example, draconian sanctions for executives. Another promising direction is to assess the benefits and powers of new control modes, for example; how trust has proven to be very powerful in governing business relations. Moreover, research on management incentives can be pushed in other directions. Since monetary rewards have proven not to be optimal incentives, boards should be willing to find incentives that do not trigger self-interested behavior, e.g., a focus on intrinsic motivations.

A second proposition is the hubris hypothesis (Roll 1986). According to this hypothesis managers systematically overestimate their abilities. They are convinced that they have the ability to identify hidden synergies and pick promising targets that others cannot (Doukas and Petmezas 2007, p. 537). To date only few measures for managerial hubris exist, e.g., in terms of media praise for the CEO (see, e.g. Chatterjee and Hambrick 2007; Hayward and Hambrick 1997; Malmendier and Tate 2005; Malmendier and Tate 2008). If a management's hubris is the major driver for acquisition decisions, it is a good alternative to consider external opinions, such as investment banks or consultancies. Acquisition plans can also be reviewed internally by acquisition committees. Since management hubris occurs subconsciously and is a form of delusion it cannot be regulated by the individual. Therefore it is different from the managerial motives which result in conscious self-serving behavior such as empire building. Hence, future research should assess which institutions are in the strongest position to limit management decisions affected by hubris. A good starting point would be the literature on decision traps (Russo and Schoemaker 1990) and psychological economics (Kahnemann and Tversky 1986). A combination of these two research avenues promises to explain the extent of M\&A activities.

\section{Appendix A}

See Tables 10 and 11.

Table 10 Operationalization of relatedness and firm size within the studies

\section{Business relatedness}

2 and 4-digit SIC industries measure of diversification, approach of Rumelt (1974): firms in different IO industries merge and the merging firms show no vertical relatedness

2 and 4-digit SIC industries measure of entropy, approach of Palepu (1985)

Conglomerate/unrelated mergers as classified by the FTC, Rumelt (1974) typology

Extent to which an acquiring firm's primary SIC codes were related to the target firm's primary SIC codes

Those in the same 2- or 3-digit industry as an acquirer's primary industry

Combination potential 
Table 10 continued

Extent of backward (supplier) and forward (processing or distributing) linkage

Percentage of acquired assets of the same 2-digit SIC code as the acquirer

Similarity between acquirers and targets on strategic variables

Judges classified the acquisition as 'related'

Interviews with managers

Firms that produced similar products or served the same or similar customers

Relatedness of the acquisition as indicated by respondents

Expansion took place within a firms value-added chain...

\section{Culture relatedness}

National cultural distance through the Kogut and Singh (1988) index based on the differences in country scores on each of Hofstede's (1980) four dimensions of national culture, i.e., uncertainty avoidance, power distance, individualism, and masculinity

Cultural differences index across several dimensions

Cultural distance, based on Ronen and Shenkar's (1985) classification (RSINDEX; ranging from 1, when the host country belonged to the Nordic block, to 8, in the case of Africa).

Crossborder mergers comparing the headquarters in different countries

Domestic expansion, foreign expansion

Share of international M\&As in the total number of its M\&As as registered according to the home country of the headquarters of companies during the period

Comparing manager responses

\section{Technology relatedness}

Diversity measure of breadth of the firm's patent stock; citation count following Hall, Jaffe, and Trajtenberg (2001); each cited patent is identified by International Patent Class (IPC) and related to the distribution of its application across industries

(Dis)similarity of the patent classification (IPC) code of the patents owned by the M\&A partners at the three digit level

Common technology base

Presence of technological relationships between acquirer and target.

List of patent numbers that appeared in both the acquired firm's knowledge base and in the acquiring firm's knowledge base

\section{Size relatedness}

Ratio of target to acquirer assets/revenues/sales/number of employees

Scales ranging from "smaller in size" to "more than ten times the size", respectively from 'smaller', '3-5 times the size', to 'more than 10 times the size' as indicated by respondents

\section{Absolute size acquirer}

Number of employees, assets, sales

Table 11 Operationalization of acquisition performance within the studies

\section{Shareholder value}

Abnormal returns (CAR, MCAR), wealth effects, performance in market share, earning per share growth, Stock Returns, Percent change in market value

\section{Accounting performance}

(Growth in) EBITDA, ROA, ROE, ROS, Sales, net income (after taxes), total assets

Scales about growth in Sales, etc. as indicated by respondents 
Table 11 continued

\section{Skill transfer and combination}

Leverage of innovation capabilities based on patent authorship data; when an inventor previously employed by the acquired firm is the author of a patent filed by the acquirer subsequent to the acquisition

Knowledge leverage; post acquisition an acquirer's patent citing an acquired firm patent Change in R\&D intensity, new product intensity, number of patents, patent intensity growth

Asking managers about skill transfer, resource transfer, new product development, performance in technological and commercial innovation, new R\&D fields and sources, etc.

\section{Overall acquisition performance}

Items to capture the extent of synergy realization from a merger or acquisition, including realized benefits from purchasing, production, marketing, market power, administration, vertical economies, new market access, cross-selling, transfer of current know-how, creation of new know-how, and other substantial synergy sources that may be described in a case

Expert evaluation (executives, analysts) of finanical and strategic benefits from the acquisition

\section{Longevity}

Number of years that the venture persisted

Acquired company was divested by the parent (yes/no)

\section{Appendix B}

\section{Studies in the Meta-Analysis}

Ahuja G, Katila R (2001) Technological acquisitions and the innovation performance of acquiring firms: a longitudinal study. Strateg Manag J 22:197220

Amit R, Livnat J (1988) Diversification stragegies, business cycles and economicperformance. Strateg Manag J 9:99-110

Barkema HG, Bell JHJ, Pennings JM (1996) Foreign entry, cultural barriers, and learning. Strateg Manag J 17:151-166

Barkema HG, Vermeulen F (1998) International expansion through start-up or acquisition: a learning perspective. Acad Manag J 41:7-26

Baysinger B, Hoskisson RE (1989) Diversification strategy and R\&D intensity in multiproduct firms. Acad Manag J 32:310-332

Bergh D D (1997) Predicting divestiture of unrelated acquisitions: an integrative model of Ex Ante conditions. Strateg Manag J 18:715-731 
Bruton GD, Oviatt BM, White MA (1994) Performance of acquisitions of distressed firms. Acad Manag J 37:972-989

Buchholtz AK, Ribbens BA, Houle IT (2003) The role of human capital in postacquisition ceo departure. Acad Manag J 46:506-514

Cannella AA, Hambrick DC (1993) Effects of executive departues on the performance of acquired firms. Strateg Manag J 14:137-152

Capon $\mathrm{N}$ et al (1988) Corporate diversity and economic performance: the impact of market specialization. Strateg Manag J 9:61-74

Capron L, Pistre N (2002) When do acquirers earn abnormal returns? Strateg Manag J 23:781-794

Cassiman B et al (2005) The impact of M\&a on the R\&D process-an empirical analysis of the role of technological- and market-relatedness. Res Policy 34:195220

Chakrabarti AK (1990) Organizational factors in post-acquisition performance. IEEE Trans Eng Manag 37:259-268

Chatterjee S (1986) Types of synergy and economic value: the impact of acquisitions on merging and rival firms. Strateg Manag J 7:119-139

Chatterjee S et al (1992) Cultural differences and shareholder value in related mergers: linking equity and human capital. Strateg Manag J 13:319-334

Chatterjee S, Wernerfelt B (1991) The link between resources and type of diversification: theory and evidence. Strateg Manag J 12:33-48

Datta DK (1991) Organizational fit and acquisition performance: effects of postacquisition integration. Strateg ManagJ 12:281-297 
Datta DK, Pinches GE, Narayanan VK (1992) Factors influencing wealth creation from mergers and acquisitions: a meta-analysis. Strateg Manag J 13:67-84

Dessyllas P, Hughes A (2005) R\&D and patenting activity and the propensity to acquire in high technology industries. Working Paper No. 298, ESRC Centre for Business Research, University of Cambridge

Dewenter K L (1995) Does the market react differently to domestic and foreign takeover announcements? Evidence from the US chemical and retail industries $\mathbf{J}$ Financ Econ 37:421-441

Donohoe SO (2006) Shareholder returns in domestic and cross border acquisitions: empirical evidence from the Uk in the fifth merger wave. Department of Accounting and Economics, Waterford Institute of Technology

Fan JPH, Goyal VK (2006) On the patterns and wealth effects of vertical mergers. J Business 79:877-902

Fields LP, Fraser DR, Kolarl JW (2007) Bidder returns in bancassurance mergers: is there evidence of synergy? J Bank Financ 31:3646-3662

Finkelstein S (1997) Interindustry merger patterns and resource dependence: a replication and extension of pfeffer (1972). Strateg Manag J 18:787-810

Finkelstein S, Haleblian J (2002) Understanding acquisition performance: the role of transfer effects. Org Sci 13:36-47

Flanagan D (1996) Announcement of purely related and purely unrelated mergers and shareholder returns: reconciling the relatedness paradox. J Manag 22:823835

Fowler KL, Schmidt DR (1989) Determinants of tender offer post-acquisition financial performance. Strateg Manag J 10:339-350 
Hagedoorn J, Duysters G (2002) The effect of mergers and acquisitions on the technological performance of companies in a high-tech environment. Tech Anal Strateg Manag 14:67-85

Haleblian J, Finkelstein S (1999) The influence of organizational acquisition experience on acquisition performance: a behavioral learning perspective. Admin Sci Q 44:29-56

Hambrick DC, Cannella AA (1993) Relative standing: a framework for understanding departures of acquired executives. Acad Manag J 36:733-762

Harris RS, Ravenscraft D (1991) The role of acquisitions in foreign direct investment: evidence from the US stock market. J Financ 46:825-844

Harrison JS, Hall EH, Nargundkar (1993) Resource allocation as an outcropping of strategic consistency: performance implications. Acad Manag J 36:1026-1051

Harrison JS et al (1991) Synergies and posacquisition performance - differences versus similarities in ressource allocations. J Manag 17:173-190

Hitt MA et al (1991) Effects of acquisitions on R\&D inputs and outputs. Acad Manag J 34:693-706

Hitt MA et al (1996) The market for corporate control and firm innovation. Acad Manag J 39:1084-1119

Hitt MA, Hoskisson RE, Kim H (1997) International diversification: effects on innovation and firm performance in product-diversified firms. Acad Manag J 40:767-798

Homburg C, Bucerius M (2006) Is speed of integration really a success factor of mergers and acquisitions? An analysis of the role of internal and external relatedness. Strateg Manag J 27:347-367 
Hoskisson RO, Johnson RA (1992) Corporate restructuring and strategic change: the effect on diversification strategy and R\&D intensity. Strateg Manag J 13:625634

Krishnan HA, Miller A, Judge WQ (1997) Diversification and top management team complementarity: Is performance improved by merging similar or dissimilar teams? Strateg Manag J 18:361-374

Kroll M et al (1997) Form of control: a critical determinant of acquisition performance and ceo rewards. Strateg Manag J 18:85-96

Krug JA, Nigh D (1998) Top management departures in cross-border acquisitions governance issues in an international context. J Int Manag 4:267-287

Kurokawa S (1997) Make-or- buy decisions in R\&D: small technology based firms in the United States and Japan. IEEE Tran Eng Manag 44:124-134

Kusewitt JB (1985) An exploratory-study of strategic acquisition factors relating to performance. Strateg Manag J 6:151-169

Langetieg TC, Haugen RA, Wichern DW (1980) Merger and stockholder risk. J Financ Quant Anal 15:689-717

Larsson R, Finkelstein S (1999) Integrating strategic, organizational, and human resource perspectives on mergers and acquisitions: a case survey of synergy realization. Organ Sci 10:1-26

Loree D, Chen CC, Guisinger S (2000) International acquisitions: do financial analysts take note? J World Bus 35:300-313

Lubatkin M (1987) Merger strategies and stockholder value. Strateg Manag J $8: 39-53$

Lubatkin M et al (1998) Managing mergers across borders: a two-nation exploration of a nationally bound administrative heritage. Organ Sci 9:670-684 
Lubatkin M et al (2001) Ecological investigation of firm effects in horizontal mergers. Strateg Manag J 22:335-357

Lubatkin M, Srinivasan N (1997) Merger strategies and shareholder value during times of relaxed antitrust enforcement: the case of large mergers during the 1980's. J Manag 23:59-81

Markides CC, Williamson PJ (1994) Related diversification, core competencies and corporate performance. Strateg Manag J 15:149-165

Mason RH, Goudzwaard MB (1976) Performance of conglomerate firms: a portfolio approach. J Financ 31:39-48

Miller DJ (2006) Technological diversity, related diversification, and firm performance. Strateg Manag J 27:601-619

Morck R, Shleifer A, Vishny RW (1990) Do managerial objectives drive bad acquisitions? J Financ 45:31-48

Morosini P, Shane S, Singh H (1998) National cultural distance and cross-border acquisition performance. J Int Bus Stud 29:137-158

Pennings JM, Barkema H, Douma S (1994) Organizational learning and diversification. Acad Manag J 37:608-640

Puranam P, Srikanth K (2007) What they know vs what they do: how acquirers leverage technology in acquisitions. Strateg Manag J 28:805-825

Ramaswamy K (1997) The performance impact of strategic similarity in horizontal mergers: evidence from the US banking industry. Acad Manag J 40:697-715

Singh H, Montgomery C (1987) Corporate acquisition strategies and economic performance. Strateg Manag J 8:377-387 
Slangen AHL (2006) National cultural distance and initial foreign acquisition performance: the moderating effect of integration. J World Bus 41:161-170

Swaminathan V, Murshed F, Hulland J (2008) Value creation following merger and acquisition announcements: the role of strategic emphasis alignment. J Market Res45:33-47

Vermeulen F, Barkema H (2001) Learning through acquisitions. Acad Manag J 44:457-476

Very P et al (1997) Relative standing and the performance of recently acquired european firms. Strateg Manag J 18:593-614

Weber Y, Shenkar O, Raveh A (1996) National and corporate cultural fit in mergers/acquisitions: an exploratory study. Manag Sci 42:1215-1227

Weston JF, Mansinghka SK (1971) Tests of the efficiency performance of conglomerate firm. J Financ 26:919-936

\section{References}

Ahuja G, Katila R (2001) Technological acquisitions and the innovation performance of acquiring firms: a logitudinal study. Strateg Manag J 22:197-220. doi:10.1002/smj.157

Andrade G (1999) Do appearances matter? The impact of EPS accretion and dilution on stock prices. http://ssrn.com/abstract=172868 or doi: $10.2139 /$ ssrn.10.2139/ssrn.172868

Baysinger B, Hoskisson RE (1989) Diversification strategy and R\&D intensity in multiproduct firms. Acad Manag J 32:310-332. doi:10.2307/256364

Bebchuk L, Hart O (2001) Takeover bids vs proxy fights in contests for corporate control. Harvard Law School, John M. Olin Center for Law, Economics and Business, Discussion paper series 336

Berkovitch E, Khanna N (1991) A theory of acquisition markets: mergers versus tender offers, and golden parachutes. Rev Financ Stud 4(1):149-174

Bettis RA, Hall WK (1982) Diversification strategy, accounting determined risk, and accounting determined return. Acad Manag J 25:254-264. doi:10.2307/255989

Borenstein $M$ et al. (2007) Comprehensive meta analysis (version 2)

Brown S, Warner J (1980) Measuring security price performance. J Financ Econ 8:205-257. doi: $10.1016 / 0304-405 X(80) 90002-1$

Bruner RF (2002) Does M\&A pay? A survey of evidence for the decision maker. J Appl Financ 12:48-68 Bruner RF (2005) Deals from hell: M\&A lessons that rise above the ashes. Wiley, Hoboken

Bruton GD, Oviatt BM, White MA (1994) Performance of acquisitions of distressed firms. Acad Manag J 37:972-989. doi:10.2307/256607 
Buono AF, Bowditch JL, Lewis JW (1985) When cultures collide: an anatomy of a merger. Hum Relat 38:477-500. doi:10.1177/001872678503800506

Capron L, Mitchell W (2000) Internal versus external knowledge sourcing: evidence from telecom operators in Europe. Working paper, INSEAD

Cassiman B et al (2005) The impact of M\&A on the R\&D process: an empirical analysis of the role of technological- and market-relatedness. Res Policy 34:195-220. doi:10.1016/j.respol.2005.01.002

Chakrabarti AK (1990) Organizational factors in post-acquisition performance. IEEE Trans Eng Manag 37:259-268. doi:10.1109/17.62321

Chatterjee S (1986) Types of synergy and economic value: the impact of acquisitions on merging and rival firms. Strateg Manag J 7:119-139. doi:10.1002/smj.4250070203

Chatterjee A, Hambrick DC (2007) It's all about me: narcissistic chief executive officers and their effects on company strategy and performance. Adm Sci Q 52:352-386

Chatterjee S, Wernerfelt B (1991) The link between resources and type of diversification: theory and evidence. Strateg Manag J 12:33-48. doi:10.1002/smj.4250120104

Chatterjee $S$ et al (1992) Cultural differences and shareholder value in related mergers: linking equity and human capital. Strateg Manag J 13:319-334. doi:10.1002/smj.4250130502

Cloodt M, Hagedoorn J, Van Kranenburg H (2006) Mergers and acquisitions: their effect on the innovative performance of companies in high-tech industries. Res Policy 35:642-654. doi: 10.1016/j.respol.2006.02.007

Cohen WL, Levinthal DM (1990) Absorptive capacity: a new perspective on learning and innovation. Adm Sci Q 35:128-152. doi:10.2307/2393553

Dalton DR et al (2003) Meta-analysis of financial performance and equity: Fusion or confusion? Acad Manag J 46:13-26

Datta DK (1991) Organizational fit and acquisition performance: effects of post-acquisition integration. Strateg Manag J 12:281-297. doi:10.1002/smj.4250120404

Datta D, Rajagopalan N, Rasheed AMA (1991) Diversification and performance: critical review and future directions. J Manag Stud 28(5):529-558

Datta DK, Pinches GE, Narayanan VK (1992) Factors influencing wealth creation from mergers and acquisitions: a meta-analysis. Strateg Manag J 13:67-84. doi:10.1002/smj.4250130106

Davis PS et al (1992) Business unit relatedness and performance: a look at the pulp and paper industry. Strateg Manag J 13:349-361. doi:10.1002/smj.4250130504

Doukas JA, Petmezas D (2007) Acquisitions, overconfident managers and self-attribution bias. Eur Financ Manag 13:531-577. doi:10.1111/j.1468-036X.2007.00371.x

Eisend M (2004) Metaanalyse. Einführung und kritische Diskussion. Betriebswirtschaftliche Reihe, Fachbereich Wirtschaftswissenschaft der Freien Universität Berlin, p 8

Ficery K, Herd T, Pursche B (2007) Where has all the synergy gone? The M\&A puzzle. J Bus Strateg 28:29-35. doi:10.1108/02756660710820802

Finkelstein S, Haleblian J (2002) Understanding acquisition performance: the role of transfer effects. Organ Sci 13:36-47. doi:10.1287/orsc.13.1.36.539

Flanagan D (1996) Announcement of purely related and purely unrelated mergers and shareholder returns: reconciling the relatedness paradox. J Manag 22:823-835. doi:10.1177/014920639602200602

Flanagan D, O'Shaugnessy KC (2003) Core-related acquisitions, multiple bidders and tender offer premiums. J Bus Res 56:573-585. doi:10.1016/S0148-2963(01)00269-7

Fluck Z, Lynch AW (1999) Why do firms merge and then divest? a theory of financial synergy. J Bus 72:319-346. doi:10.1086/209617

Fuller K, Netter J, Stegemoller M (2002) What do returns to acquiring firms tell us? evidence from firms that make many acquisitions. J Financ 57:1763-1793. doi:10.1111/1540-6261.00477

Gugler K et al (2003) The effects of mergers: an international comparison. Int J Ind Organ 21:625-653. doi:10.1016/S0167-7187(02)00107-8

Hagedoorn J, Duysters G (2002) The effect of mergers and acquisitions on the technological performance of companies in a high-tech environment. Technol Anal Strateg Manag 14:67-85. doi:10.1080/ 09537320220125892

Hall BH, Jaffe A, Trajtenberg M (2001) The NBER patent citations data file: lessons, insights and methodological tools, Working paper no. 8498, NBER

Hambrick D, Cannella A (1993) Relative standing: a framework for understanding departures of acquired executives. Acad Manag J 36:733-762. doi:10.2307/256757

Harrison JS, Hall EH, Nargundkar (1993) Resource allocation as an outcropping of strategic consistency: performance implications. Acad Manag J 36:1026-1051. doi:10.2307/256644 
Hayward MLA, Hambrick DC (1997) Explaining the premiums paid for large acquisitions: evidence of CEO hubris. Adm Sci Q 42:103-127. doi:10.2307/2393810

Healy PM, Palepu KG, Ruback RS (1997) Which takeovers are profitable? Strategic or financial? Sloan Bus Rev 38:45-57

Heeley MB, King DR, Covin JG (2006) Effects of firm R\&D investment and environment on acquisition likelihood. J Manag Stud 43:1514-1535. doi:10.1111/j.1467-6486.2006.00636.x

Hitt MA et al (1991) Effects of acquisitions on R\&D inputs and outputs. Acad Manag J 34:693-706. doi: $10.2307 / 256412$

Hitt MA et al (1996) The market for corporate control and firm innovation. Acad Manag J 39:1084-1119. doi: $10.2307 / 256993$

Hofstede G (1980) Culture's consequences: international differences in work-related values. Sage Publications, Berverly Hills

Hofstede G (2001) Culture's consequences-comparing values, behaviors. Institutions and Organizations across Nations, Thousand Oaks

Hunter JE, Schmidt FL (2004) Methods of meta-analysis: correcting error and bias in research findings. Sage Thousand Oaks, London

Jansen SA (2002) Die 7 K's des Merger Managements. Zeitschrift für Organisation 71(1):6-13

Jensen MC, Ruback RS (1983) The market for corporate control: the scientific evidence. J Financ Econ 11(1):5-50

Kahnemann D, Tversky A (1986) Rational choice and the framing of decisions. J Bus 59:251-278. doi: $10.1086 / 296367$

Kiechel WI (2007) Private equity's long view. Harv Bus Rev 85:18-19

King DR et al (2004) Meta-analyses of post-acquisition performance: indications of unidentified moderators. Strateg Manag J 25:187-200. doi:10.1002/smj.371

Kogut B, Singh H (1988) The effect of national culture on the choice of entry mode. J Int Bus Stud 19:411-432. doi:10.1057/palgrave.jibs.8490394

Köppen J, Knyphausen-Aufseß DZ (2004) Akquisitionsprämien und Lebensdauer von Synergien entscheiden über den Erfolg eines Mergers. M\&. Rev 5:467-475

Kothari SP, Warner JB (2004) Econometrics of event studies. http://ssrn.com/abstract=608601

Krishnan HA, Hitt MA, Park D (2007) Acquisition premiums, subsequent workforce reductions and postacquisition performance. J Manag Stud 44:709-732. doi:10.1111/j.1467-6486.2006.00672.x

Kumar MS (1985) Growth, acquisition activity and firm size: evidence from the United Kingdom. J Ind Econ 33:327-338. doi:10.2307/2098540

Kürsten W (2008) Synergies, shareholder value and exchange ratios in "value-creating" mergers: why shareholders should doubt management's pre-merger promises. Manag Financ 34:252-261. doi: $10.1108 / 03074350810849288$

Kusewitt JB (1985) An exploratory study of strategic acquisition factors relating to performance. Strateg Manag J 6:151-169. doi:10.1002/smj.4250060205

Laincz CA, Rodrigues ASD (2005) A theoretical foundation for understanding firm size distributions and Gibrat's law. Discussion paper, University of York, England

Larsson R, Finkelstein S (1999) Integrating strategic, organizational, and human resource perspectives on mergers and acquisitions: a case survey of synergy realization. Organ Sci 10:1-26. doi:10.1287/ orsc.10.1.1

Larsson R, Lubatkin MH (2001) Achieving acculturation in mergers and acquisitions: an international case survey. Hum Relat 54:1573-1607

Leland HE (2007) Financial synergies and the optimal scope of the firm: implications for mergers, spinoffs, and structured finance. J Financ 62:765-807. doi:10.1111/j.1540-6261.2007.01223.x

Limmack R, McGregor N (1995) Industrial relatedness, structural factors and bidder returns. Appl Financ Econ 5:179-190. doi:10.1080/758523005

Lindenberg E, Ross MP (1999) To purchase or to pool: does it matter? J Appl Corp Financ 12:32-48. doi: 10.1111/j.1745-6622.1999.tb00006.x

Lubatkin M (1987) Merger strategies and stockholder value. Strateg Manag J 8:39-53. doi: 10.1002/smj.4250080105

Lubatkin M, Srinivasan N (1997) Merger strategies and shareholder value during times of relaxed antitrust enforcement: the case of large mergers during the 1980's. J Manag 23:59-81. doi:10.1177/ 014920639702300104

MacKinlay CA (1997) Event studies in economics and finance. J Econ Lit 35:13-39 
Malmendier U, Tate G (2005) Does overconfidence affect corporate investment? CEO overconfidence measures revisited. Eur Financ Manag 11:649-659. doi:10.1111/j.1354-7798.2005.00302.x

Malmendier U, Tate G (2008) Who makes acquisitions? CEO overconfidence and the market's reaction. J Financ Econ 89:20-43. doi:10.1016/j.jfineco.2007.07.002

Markides CC, Williamson PJ (1994) Related diversification, core competences and corporate performance. Strateg Manag J 15:149-166

Miller DJ (2006) Technological diversity, related diversification, and firm performance. Strateg Manag J 27:601-619. doi:10.1002/smj.533

Moeller SB, Schlingemann FP, Stulz RM (2004) Firm size and the gains from acquisitions. J Financ Econ 73:201-228. doi:10.1016/j.jfineco.2003.07.002

Montgomery C, Singh H (1987) Corporate acquisition strategies and economic performance. Strateg Manag J 8:377-386. doi:10.1002/smj.4250080407

Morck R, Shleifer A, Vishny RW (1990) Do managerial objectives drive bad acquisitions? J Financ 45:31-48. doi:10.2307/2328808

Morosini P, Shane S, Singh H (1998) National cultural distance and cross-border acquisition performance. J Int Bus Stud 29:137-158. doi:10.1057/palgrave.jibs.8490029

Mueller DC (1997) Merger policy in the united states: a reconsideration. Rev Ind Organ 12:655-685. doi: 10.1023/A:1007797626160

Müller-Stewens G, Lechner C (2003) Strategisches Management-Wie strategische Initiativen zum Wandel führen? Schäffer-Pöschel, Stuttgart

Orwin RG (1994) Evaluating coding decisions. In: Cooper HHedges LV (ed) The handbook of research synthesis. Russell Sage Foundation, New York, pp 139-162

Palepu K (1985) Diversification strategy, profit performance and the entropy measure. Strateg Manag J 6:239-255. doi:10.1002/smj.4250060305

Palich LE, Cardinal LB, Miller CC (2000) Curvilinearity in the diversification-performance linkage: an examination of over three decades of research. Strateg Manag J 21(2):155-174

Papadakis VM (2005) The role of broader context and the communication program in merger and acquisition implementation success. Manag Decis 43:236-255. doi:10.1108/00251740510581948

Pennings JM, Barkema H, Douma S (1994) Organizational learning and diversification. Acad Manag J 37:608-640. doi:10.2307/256702

Porter M (1985) Competitive advantage: creating and sustaining superior performance. Free Press, New York

Prahalad CK, Bettis RA (1986) The dominant logic: a new linkage between diversity and performance. Strateg Manag J 7:485-501

Puranam P, Srikanth K (2007) What they know vs what they do: how acquirers leverage technology in acquisitions. Strateg Manag J 28:805-825. doi:10.1002/smj.608

Rappaport A (1986) Creating shareholder value: the new standard for business performance. Free Press, New York

Ravenscraft DJ, Scherer FM (1989) The profitability of mergers. Int J Ind Organ 7:101-116. doi: 10.1016/0167-7187(89)90048-9

Robinson JR, Shane PB (1990) Acquisition accounting method and bid premia for target firms. Account Rev 65:25-48

Roll R (1986) The hubris hypothesis of corporate takeovers. J Bus 59:197-216. doi:10.1086/296325

Ronen S, Shenkar O (1985) Clustering countries on attitudinal dimensions: a review and synthesis. Acad Manag Rev 10(3):435-454

Rumelt R (1974) Strategy, structure, and economic performance. Harvard Business School Press, Boston

Russo EJ, Schoemaker PJH (1990) Decision traps. Simon \& Schuster Inc., New York

Salter MS, Weinhold WA (1978) Diversification via acquisition: creating value. Harv Bus Rev 56:166176

Scanlon KP, Trifts JW, Pettway RH (1989) Impacts of relative size and industrial relatedness on returns to shareholders of acquiring firms. J Financ Res 12:103-112

Schoenberg R (2006) Measuring performance of corporate acquisitions: an empirical comparison of alternative metrics. Br J Manag 17:361-370. doi:10.1111/j.1467-8551.2006.00488.x

Seth A (1990) Value creation in acquisitions: a re-examination of performance issues. Strateg Manag J 11:99-115. doi:10.1002/smj.4250110203

Singh H, Montgomery C (1987) Corporate acquisition strategies and economic performance. Strateg Manag J 8:377-387. doi:10.1002/smj.4250080407

Sirower M (2001) Der Synergieeffekt. FinanzBuch Verlag, München 
Slangen AHL (2006) National cultural distance and initial foreign acquisition performance: the moderating effect of integration. J World Bus 41:161-170. doi:10.1016/j.jwb.2006.01.003

Stahl GK, Voigt A (2008) Do cultural differences matter in merger and acquisitions? a tentative model and examination. Organ Sci 19:160-176. doi:10.1287/orsc.1070.0270

Sudarsanam SP (1995) The essence of mergers and acquisitions. Prentice Hall, Hemel Hempstead

Sudarsanam S, Holl P, Salami A (1996) Shareholder wealth gains in mergers: effect of synergy and ownership structure. J Bus Financ Account 23:673-695. doi:10.1111/j.1468-5957.1996.tb01148.x

Tosi HL et al (2000) How much does performance matter? A meta-analysis of CEO pay studies. J Manag 26:301-339. doi:10.1177/014920630002600207

Traijtenberg M (1990) A penny for your quotes: patent citations and the value of inventions. RAND J Econ 20(4):172-187

Tschöke K, Csanad D (2007) Der globale M\&A-Markt im zweiten Quartal 2007. M\&. Rev 17:380-386

Tuch C, O'Sullivan N (2007) The impact of acquisitions on firm performance: a review of evidence. Int J Manag Rev 9:141-170. doi:10.1111/j.1468-2370.2007.00206.x

Vermeulen F, Barkema H (2001) Learning through acquisitions. Acad Manag J 44:457-476. doi: $10.2307 / 3069364$ 